\title{
Quantifying the impact of financial development on economic development
}

\author{
Jeremy Greenwood ${ }^{\mathrm{a}}$, Juan M. Sanchez ${ }^{\mathrm{b}, *}$, Cheng Wang ${ }^{\mathrm{c}, \mathrm{d}}$ \\ a Department of Economics, University of Pennsylvania, McNeil Bldg., Rm 160, Philadelphia, PA 19104-6927, USA \\ ${ }^{\mathrm{b}}$ Research Division, Federal Reserve Bank of St. Louis, P.O. Box 442, St. Louis, MO 63166-0442, USA \\ c School of Economics, Fudan University, Shanghai 200433, China \\ d Department of Economics, Iowa State University, 260 Heady Hall, Ames, IA 50011-1070, USA
}

\section{A R T I C L E I N F O}

\section{Article history:}

Received 12 February 2011

Revised 14 May 2012

Available online 27 July 2012

\section{JEL classification:}

E13

011

016

Keywords:

Costly state verification

Economic development

Financial intermediation

Firm-size distributions

Interest-rate spreads

Cross-country output differences

Cross-country differences in financial sector

productivity

Cross-country TFP differences

\begin{abstract}
A B S T R A C T
How important is financial development for economic development? A costly state verification model of financial intermediation is presented to address this question. The model is calibrated to match facts about the U.S. economy, such as the intermediation spreads and the firm-size distributions for 1974 and 2004. It is then used to study the international data using cross-country interest-rate spreads and per-capita GDPs. The analysis suggests a country like Uganda could increase its output by 116 percent if it could adopt the world's best practice in the financial sector. Still, this amounts to only 29 percent of the gap between Uganda's potential and actual output.
\end{abstract}

(C) 2012 Elsevier Inc. All rights reserved.

\section{Introduction}

How important is financial development for economic development? Ever since the publication of Raymond W. Goldsmith's (1969) classic book Financial Structure and Development, economists have been developing theories and searching for empirical evidence connecting economic and financial development. Goldsmith emphasized the role that intermediaries play in steering funds to the highest-valued users in the economy. First, intermediaries collect and analyze information before they invest in businesses. Based on this information, they determine whether to commit savers' funds. If they proceed, then they must decide how much to invest and on what terms. Second, after allocating funds intermediaries must monitor firms to ensure that savers' best interests are protected. Increases in the efficiency of financial intermediation, due to improved information production, are likely to reduce the spreads between the internal rates of return on investments in firms and the rate of return on savings received by savers. The spreads between these returns reflect the costs of intermediation. These intermediation wedges include the costs of gathering ex ante information about investment projects, the ex post

\footnotetext{
* Corresponding author. Fax: +1 (314) 4448731.

E-mail address: juan.m.sanchez78@gmail.com (J.M. Sanchez).
} 
United States

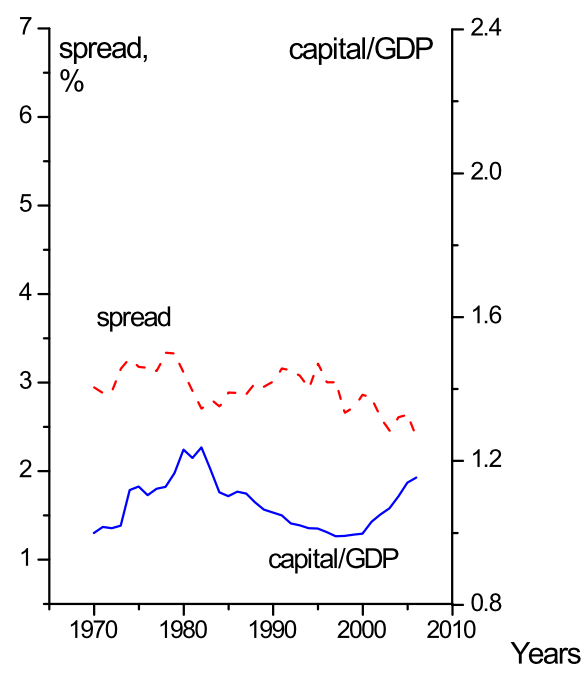

Taiwan

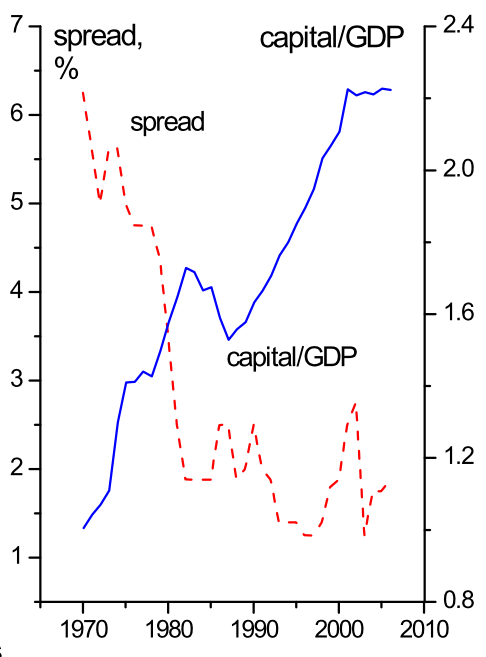

Fig. 1. Interest-rate spreads and capital-to-GDP ratios for the United States and Taiwan, 1970-2005. Data sources for all figures are discussed in Appendix A.

information costs of policing investments, and the costs of misappropriation of savers' funds by management, unions, and so on that arise in a world with imperfect information. An improvement in financial intermediation does not necessarily affect the rate of return earned by savers. Aggregate savings may adjust in equilibrium so that this return always equals savers' rate of time preference.

The left panel of Fig. 1 plots the intermediation wedge for the U.S. economy over time. (All data definitions are presented in Appendix A.) The United States is a developed economy with a sophisticated financial system. The wedge falls only slightly. At the same time, it is difficult to detect an upward trend in the capital-to-output ratio. Contrast this with Taiwan (shown in the right panel): There is a dramatic drop in the interest-rate spread. As the cost of capital falls, one would expect to see a rise in investment. Indeed, the capital-to-output ratio for Taiwan shows a significant increase. The observation that there is only a small drop in the U.S. interest-rate spread does not imply that there has been no technological advance in the U.S. financial sector. Rather, it may reflect the fact that efficiency in the U.S. financial sector has grown in tandem with the rest of the economy, while for Taiwan it has outpaced it. For without technological advance in the financial sector, banks would face a losing battle with the rising labor costs that are inevitable in a growing economy. The intermediation spread would then have to rise to cover costs; more on this later.

Now, in Goldsmithian fashion, consider the scatterplots presented for a sample of countries in Figs. 2 and 3 . The left panel in Fig. 2 shows that countries with lower interest-rate spreads tend to have higher capital-to-gross domestic product (GDP) ratios. The right panel illustrates that a higher capital-to-GDP ratio is associated with a greater level of GDP per capita. Dub this the capital-deepening effect of financial intermediation. Next, turn to the left panel in Fig. 3. Observe that lower interest-rate spreads are also linked with higher levels of total factor productivity, TFP. This would happen when better intermediation tends to redirect funds to the more efficient firms. The right panel displays how higher levels of TFP are connected with larger per-capita GDP. Call this the reallocation effect arising from financial intermediation. The capital-deepening and reallocation effects from improved intermediation play an important role in what follows. While the above facts are stylized, to be sure, empirical researchers have used increasingly sophisticated methods to tease out the relationship between financial intermediation and growth. This literature is surveyed masterfully by Levine (2005). An early example of the empirical research examining the link between financial intermediation and growth is the well-known paper by King and Levine (1993). The upshot is that financial development has a causal effect on economic development; specifically, financial development leads to higher rates of growth in income and productivity.

The impact of financial development on economic development is investigated here, quantitatively, using a costly state verification model that was developed by Greenwood et al. (2010). The source of inspiration for the framework is the classic work by Townsend (1979) and Williamson (1986). It has two novel twists, though. First, firms monitor cash flows as in Townsend (1979) and Williamson (1986); however, here the efficiency of this activity depends on both the amount of resources devoted to it and the productivity of the monitoring technology used in the financial sector. Second, firms have ex ante differences in the structure of returns that they offer. A financial theory of firm size emerges. At any point in time, firms offering high expected returns are underfunded (relative to a world without informational frictions), whereas others yielding low expected returns are overfunded. This results from diminishing returns in information production. As the efficiency of the financial sector rises (relative to the rest of the economy), funds are redirected away from less productive firms in the economy toward more productive ones. Furthermore, as the interest-rate spread declines and the cost of borrowing falls, capital deepening occurs in the economy. 

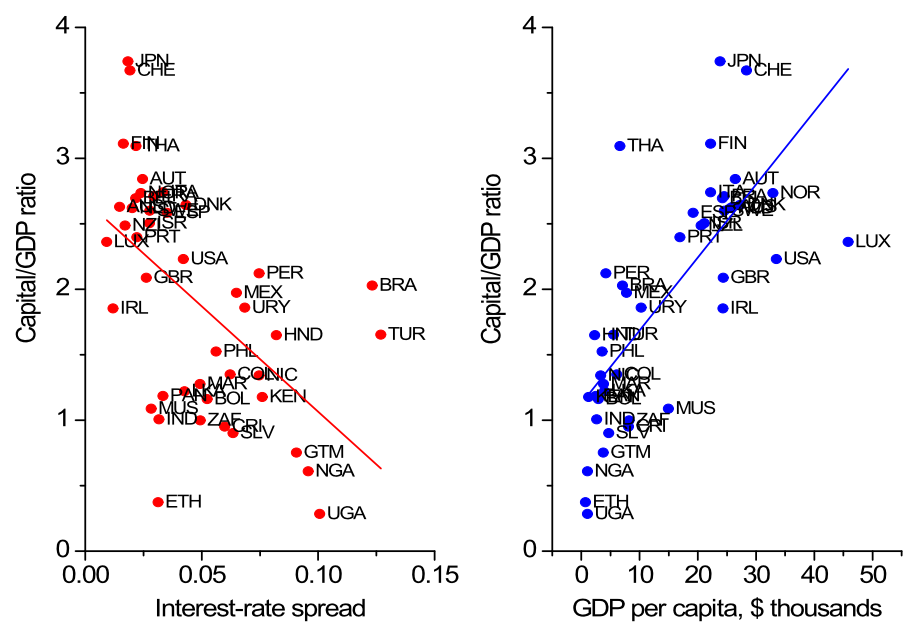

Fig. 2. The cross-country relationship among interest-rate spreads, capital-to-GDP ratios and GDPs per capita. The three letter country codes are taken from the International Organization for Standardization, ISO 3166-1 alpha-3.
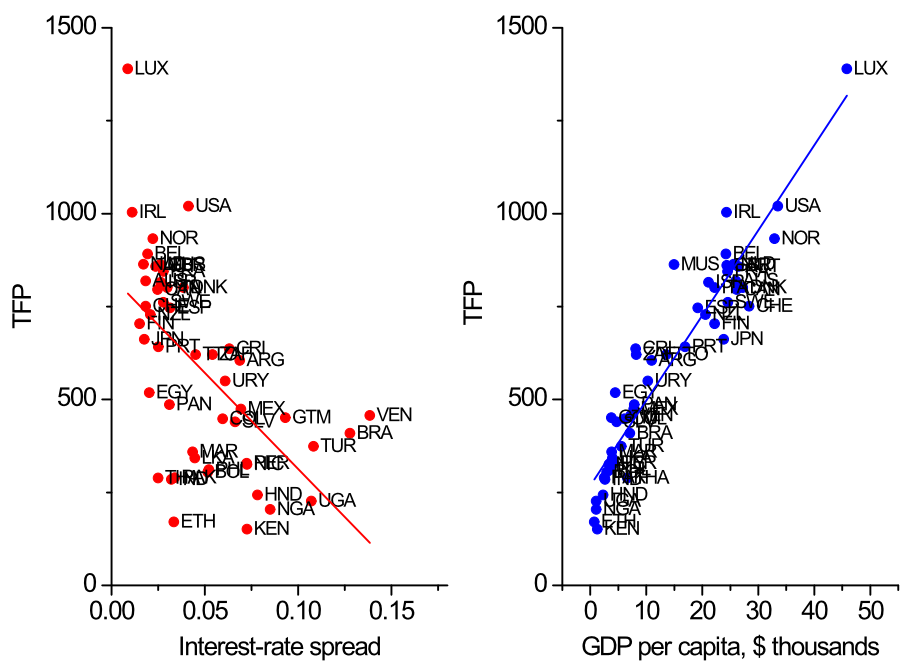

Fig. 3. The cross-country relationship among interest-rate spreads, TFPs and GDPs per capita.

The model is calibrated to match some stylized facts for the U.S. economy, specifically the firm-size distributions and interest-rate spreads for the years 1974 and 2004. It replicates these facts very well. The improvement in financial sector productivity required to duplicate these facts also appears to be reasonable; it does this with little change in the capital-tooutput ratio. In the model, improvements in financial intermediation account for 29 percent of U.S. growth. The framework also is capable of mimicking the striking decline in the Taiwanese interest-rate spread. At the same time, it predicts a significant rise in the capital-to-output ratio. It is estimated that dramatic improvements in Taiwan's financial sector accounted for 45 percent of the country's economic growth.

The calibrated model is then applied to the cross-country data. It performs reasonably well in predicting the differences in cross-country capital-to-output ratios. Similarly, it does a good job of matching the empirical relationship between financial development and average firm size. Financial intermediation turns out to be important quantitatively. For example, in the baseline model Uganda would increase its per-capita GDP by 116 percent if it could somehow adopt Luxembourg's financial system. World output would rise by 53 percent if all countries adopted Luxembourg's financial practice. Still, the bulk (or 69 percent) of cross-country variation in per-capita GDP cannot be accounted for by variation in financial systems.

Other researchers have recently investigated the relationship between finance and development using quantitative models. The frameworks used, and the questions addressed, differ from the current analysis. For example, Townsend and Ueda (2010) estimate a version of the Greenwood and Jovanovic (1990) model to examine Thai financial reform. Their analysis stresses the role of financial intermediaries in producing ex ante information about the state of the economy at the aggregate level. Financial intermediaries offer savers higher and safer returns. Townsend and Ueda (2010) find that Thai welfare increased about 15 percent due to financial liberalization. 
Limited investor protection is emphasized by Castro et al. (2009). They build a two-sector model to explain the positive cross-country correlation between investment and GDP. They note that the capital-goods sector is risky. This risk makes capital goods expensive to produce in poor countries with limited investor protection because of high finance costs. An implication of their framework is that the correlation between investment and GDP is weaker when measured at domestic vis-à-vis international prices. This is true in the data. A close cousin to the notion of limited investor protection is the idea of limited enforceability of contracts. Buera et al. (2011) focus on the importance of limited enforceability of contracts in distorting the allocation of entrepreneurial talent in the economy. This helps explain TFP differentials across nations. The interplay between the enforceability of contracts and the allocation of managerial talent for explaining cross-country productivity differences is also investigated by Erosa and Cabrillana (2008) in a similar framework, albeit with more of a theoretical emphasis. Finally, Midrigan and Xu (2010) challenge the view that the borrowing constraints induced by limited enforceability of contracts create large reallocation effects via the distortion of factor inputs across firms. They argue that firms can quickly grow out of the implied borrowing constraints. ${ }^{1}$

\section{The economy}

The analysis focuses on two types of agents: firms and financial intermediaries. Firms produce output using capital and labor. Their production processes are subject to idiosyncratic productivity shocks. The realized value of the productivity shock is a firm's private information. All funding for capital must be raised from financial intermediaries. This is done before the technology shock is observed. After seeing its shock, a firm hires labor on a spot market. When financing its capital a firm enters into a financial contract with an intermediary. This contract specifies the state-contingent payment that a firm must make to an intermediary on completing production. Hidden in the background are consumers/workers, who supply a fixed amount of labor to the economy. They also deposit funds with an intermediary that earn a fixed rate of return. Given the focus here on comparative steady states, an analysis of consumers/workers can be safely suppressed. The behavior of firms and intermediaries is described below in more detail.

\subsection{Firms}

Firms hire capital, $k$, and labor, $l$, to produce output, $o$, in line with the constant-returns-to-scale production function

$$
0=x \theta k^{\alpha} l^{1-\alpha} .
$$

The productivity level of a firm's production process is represented by $x \theta$. It is the product of two components: an aggregate one, $x$, and an idiosyncratic one, $\theta$. The idiosyncratic level of productivity is a random variable. Specifically, the realized value of $\theta$ is drawn from the two-point set $\tau=\left\{\theta_{1}, \theta_{2}\right\}$, with $\theta_{1}<\theta_{2}$. The set $\tau$ differs across firms. Call this the firm's type. Let $\operatorname{Pr}\left(\theta=\theta_{1}\right)=\pi_{1}$ and $\operatorname{Pr}\left(\theta=\theta_{2}\right)=\pi_{2}=1-\pi_{1}$. The probabilities for the low and high states ( 1 and 2 , respectively) are the same across firms. The realized value of $\theta \in \tau$ is a firm's private information. For now take the aggregate level of productivity, $x$, to be some known constant.

Suppose that a type- $\tau$ firm has raised $k$ units of capital. It then draws the productivity shock $\theta_{i}$. It must now decide how much labor, $l_{i}$, to hire at the wage rate $w$. In other words, the firm solves the maximization problem shown below.

$$
R\left(\theta_{i}, w\right) k \equiv \max _{l_{i}}\left\{x \theta_{i} k^{\alpha} l_{i}^{1-\alpha}-w l_{i}\right\} .
$$

Denote the optimal amount of labor that a type- $\tau$ firm will hire in state $i$ by $l_{i}(\tau)=l_{i}\left(\theta_{1}, \theta_{2}\right)$. Substituting the implied solution for $l_{i}$ into the maximand and solving yields the unit return function, $R\left(\theta_{i}, w\right)$, or

$$
r_{i}(\tau) \equiv R\left(\theta_{i}, w\right)=\alpha(1-\alpha)^{(1-\alpha) / \alpha} w^{-(1-\alpha) / \alpha}\left(x \theta_{i}\right)^{1 / \alpha}>0 .
$$

Think about $r_{i}(\tau)=R\left(\theta_{i}, w\right)$ as giving the gross rate of return on a unit of capital invested in a type- $\tau$ firm, given that state $\theta_{i}$ occurs. Finally, represent the amount of output that a type- $\tau$ firm will produce in state $i$ by

$$
o_{i}(\tau)=o_{i}\left(\theta_{1}, \theta_{2}\right)=x \theta_{i} k\left(\theta_{1}, \theta_{2}\right)^{\alpha} l_{i}\left(\theta_{1}, \theta_{2}\right)^{1-\alpha},
$$

where $k(\tau)=k\left(\theta_{1}, \theta_{2}\right)$ is the size of the loan that will be received by this firm. The next section discusses how this loan is determined.

\subsection{Financial intermediaries}

Intermediation is competitive. Intermediaries raise funds from consumers and lend them to firms. Even though an intermediary knows a firm's type, $\tau$, it cannot observe the state of a firm's business either costlessly or perfectly. That is,

\footnotetext{
1 Additionally, dynamic contracts can potentially be used to mitigate such financial frictions. See Cole et al. (2012) for an analysis of technological adoption across countries using a framework with dynamic contracts for firm finance.
} 
the intermediary cannot costlessly observe $\theta, o$, and $l$. Suppose a firm's true productivity in a period is $\theta_{i}$. It reports to the intermediary that its productivity is $\theta_{j}$, which may differ from $\theta_{i}$. The intermediary can audit this report. It seems reasonable to presume that the odds of detecting fraud are increasing in the amount of labor devoted to verifying the claim, $l_{m j}$, decreasing in the size of the loan, $k$ (because there will be more activity to monitor), and rising in the productivity of the monitoring technology, $z$.

Let $P_{i j}\left(l_{m j}, k, z\right)$ denote the probability that the firm is caught cheating conditional on the following: (1) the true realization of productivity is $\theta_{i}$; (2) the firm makes a report of $\theta_{j}$; (3) the intermediary allocates $l_{m j}$ units of labor to monitor the claim; (4) the size of the loan is $k$ (which represents the scale of the project); (5) the level of productivity in the monitoring activity is $z$. The function $P_{i j}\left(l_{m j}, k, z\right)$ is increasing in $l_{m j}$ and $z$ and decreasing in $k$. Additionally, let $P_{i j}\left(l_{m j}, k, z\right)=0$ if the firm truthfully reports that its type is $\theta_{i}$ (i.e., when $j=i$ ). A convenient formulation for $P_{i j}\left(l_{m j}, k, z\right)$ is ${ }^{2}$

$$
P_{i j}\left(l_{m j}, k, z\right)= \begin{cases}1-\frac{1}{\epsilon(z / k)^{\psi}\left(l_{m j}\right)^{\gamma}}<1, & \text { with } 0<\gamma<\psi<1, \text { for a report } \theta_{j} \neq \theta_{i}, \\ 0, & \text { for a report } \theta_{j}=\theta_{i} .\end{cases}
$$

Suppose that loan size, $k$, increases. Let the intermediary raise the amount of labor, $l_{m j}$, that it will use to monitor a claim of state $j$ by the same proportion. Observe that the odds of detecting malfeasance, $P_{i j}\left(l_{m j}, k, z\right.$ ), will fall (for a report of $\theta_{j} \neq \theta_{i}$ ) because $\gamma<\psi$. In this sense, there are diminishing returns to scale in monitoring.

The intermediary gives a firm a loan of size $k$. In exchange for providing the loan the intermediary collects some specified state-contingent payments from the firm. The rents that accrue to a firm depend on the true state of its technology, $\theta_{i}$, the state that it reports, $\theta_{j}$, plus the outcome of any monitoring that is done. Clearly, a firm will have no incentive to misreport when the bad state, $\theta_{1}$, occurs. Similarly, the intermediary will never monitor a good report, $\theta_{j}=\theta_{2}$; it will audit only bad ones, $\theta_{j}=\theta_{1}$. If it finds malfeasance, then the intermediary should exert maximal punishment, which amounts to seizing everything or $r_{2} k$. If it does not, then it should take all of the bad state returns, or $r_{1} k$. These latter two features help to create, in a least-cost manner, an incentive for the firm to tell the truth. The above features are embedded in the contracting problem presented below. A more formal, step-by-step analysis is presented in Greenwood et al. (2010).

Turn now to the contracting problem. Intermediation is competitive. Therefore, an intermediary must choose the details of the financial contract to maximize the expected rents for a firm. Otherwise, the firm will take out a loan elsewhere. Competition implies that all intermediaries earn zero profits on their lending activity. Suppose that intermediaries can raise funds from savers at the interest rate $\hat{r}$. If the depreciation rate on physical capital is $\delta$, then the cost of supplying capital is $\tilde{r}=\hat{r}+\delta$. The intermediary's optimization problem can be expressed $\mathrm{as}^{3}$

$$
v \equiv \max _{k, l_{m 1}}\left\{\pi_{2}\left[1-P_{21}\left(l_{m 1}, k, z\right)\right]\left[r_{2}(\tau)-r_{1}(\tau)\right] k\right\},
$$

subject to

$$
\left[\pi_{1} r_{1}(\tau)+\pi_{2} r_{2}(\tau)\right] k-\pi_{2}\left[1-P_{21}\left(l_{m 1}, k, z\right)\right]\left[r_{2}(\tau)-r_{1}(\tau)\right] k-\pi_{1} w l_{m 1}-\tilde{r} k=0
$$

The objective function $\mathrm{P}(2)$ gives the expected rents for a firm. These rents accrue from the fact that the firm has private information about its state. Suppose that the firm lies about being in the good state. When it does not get caught, it can pocket the amount $\left[r_{2}(\tau)-r_{1}(\tau)\right] k$. The odds of not getting caught are $1-P_{21}\left(l_{m 1}, k, z\right)$. The good state occurs with probability $\pi_{2}$. An incentive-compatible contract offers the firm the same amount for telling the truth that it can get by lying. ${ }^{4}$ Eq. (3) is the intermediary's zero-profit condition. The expected return from the project is $\left[\pi_{1} r_{1}(\tau)+\pi_{2} r_{2}(\tau)\right] k$. Out of this amount the intermediary must give the firm $\pi_{2}\left[1-P_{21}\left(l_{m 1}, k, z\right)\right]\left[r_{2}(\tau)-r_{1}(\tau)\right] k$. The expected cost of monitoring low-state returns is $\pi_{1} w l_{m 1}$. The cost of supplying the capital is $\tilde{r} k$. Represent the optimal amount of labor required to monitor a type- $\tau$ firm in state 1 by $l_{m 1}(\tau)=l_{m 1}\left(\theta_{1}, \theta_{2}\right)$. The contract presumes that the intermediary is committed to monitoring all reports of a bad state. Likewise, denote the quantity of capital that is lent to a type- $\tau$ firm by $k(\tau)=k\left(\theta_{1}, \theta_{2}\right)$. Finally, for some types of firms a loan may entail a loss; the intermediary will not lend to these firms.

\footnotetext{
2 To guarantee that $P_{i j}\left(l_{m j}, k, z\right) \geqslant 0$ this specification requires, when $\theta_{j} \neq \theta_{i}$, that some minimal level of labor must be devoted to monitoring; that is, $l_{m j}>\epsilon^{-1 / \gamma}(k / z)^{-\psi / / \gamma}$. Note that this minimal labor requirement for monitoring can be made arbitrarily small by picking a large enough value for $\varepsilon$. The choice of $\varepsilon$ can be thought of as normalization relative to the level of productivity in the production of monitoring services; see Greenwood et al. (2010) for more detail.

3 This is the dual of the problem presented in Greenwood et al. (2010).

${ }^{4}$ Let $p_{2}$ represent the payment that a firm makes to the intermediary in the good state. The incentive constraint for the contract will read
}

$$
\left[1-P_{21}\left(l_{1}^{m}, k, z\right)\right]\left[r_{2}(\tau)-r_{1}(\tau)\right] k \leqslant r_{2}(\tau) k-p_{2} .
$$

The left-hand side of this equation represents what the firm will obtain by lying, while the right-hand side shows what it will receive when it tells the truth. The latter must dominate, in a weak sense, the former. (Recall that upon the declaration of a bad state, the firm must turn over $r_{1}(\tau) k$ to the intermediary. So, it will make nothing when it truthfully reports a bad state. If the firm gets caught cheating, then it must make the payment $r_{2}(\tau) k$, so it will also earn zero rents here.) The incentive constraint will bind. Thus, $\mathrm{P}(2)$ maximizes the firm's expected rents, $\pi_{2}\left[r_{2}(\tau) k-p_{2}\right]$, subject to the zero-profit constraint. As in Townsend (1979), it can be shown that the revelation principle holds, so the focus here on incentive-compatible contracts is without loss of generality. 


\subsection{Stationary equilibrium}

The focus of the analysis is solely on stationary equilibria. Firms differ by type, $\tau=\left(\theta_{1}, \theta_{2}\right)$ with $\theta_{1}<\theta_{2}$. Denote the space of types by $\mathcal{T} \subseteq R_{+}^{2}$. Suppose that firms are distributed over productivities in accordance with the distribution function

$$
F(x, y)=\operatorname{Pr}\left(\theta_{1} \leqslant x, \theta_{2} \leqslant y\right) .
$$

For all firms fix the odds of drawing state $i$ at $\operatorname{Pr}\left(\theta=\theta_{1}\right)=\pi_{i}$. This distribution $F$ can then be thought of as specifying the mean, $\pi_{1} \theta_{1}+\pi_{2} \theta_{2}$, and variance, $\pi_{1} \pi_{2}\left(\theta_{1}-\theta_{2}\right)^{2}$, of project returns across firms. So, which firms will receive funding in equilibrium?

To answer this question, focus on the zero-profit condition for intermediaries (3). Now consider a firm of type $\tau$. Clearly, if $\pi_{1} r_{1}(\tau) k+\pi_{2} r_{2}(\tau) k-\tilde{r} k<0$, then the intermediary will incur a loss on any loan of size $k>0$. Likewise, if $\pi_{1} r_{1} k+$ $\pi_{2} r_{2} k-\tilde{r} k>0$, then it will be possible to make non-negative profits, albeit the loan may have to be very small. Therefore, a necessary and sufficient condition to obtain funding is that $\tau$ lies in the set $\mathcal{A}(w) \subseteq \mathcal{T}$ defined by

$$
\mathcal{A}(w) \equiv\left\{\tau: \pi_{1} r_{1}(\tau)+\pi_{2} r_{2}(\tau)-\tilde{r}>0\right\} .
$$

This set shrinks with the wage, $w$, because $r_{i}(\tau)$ is decreasing in $w$; as wages rise, a firm becomes less profitable.

Firms with $\tau \in \mathcal{A}(w)$ will demand $l_{i}\left(\theta_{1}, \theta_{2}\right)$ units of labor in state $i$. Should one of these firms declare that it is in state 1 , then the intermediary will send $l_{m 1}\left(\theta_{1}, \theta_{2}\right)$ units of labor to audit it. Recall that labor is in fixed supply. Suppose there is one unit in aggregate. The labor-market-clearing condition will then appear as

$$
\int_{\mathcal{A}(w)}\left[\pi_{1} l_{1}\left(\theta_{1}, \theta_{2}\right)+\pi_{2} l_{2}\left(\theta_{1}, \theta_{2}\right)+\pi_{1} l_{m 1}\left(\theta_{1}, \theta_{2}\right)\right] d F\left(\theta_{1}, \theta_{2}\right)=1 .
$$

It is now time to take stock of the situation thus far by presenting a definition of the equilibrium under study.

Definition 1. Set the steady-state cost of capital at $\tilde{r}$. A stationary competitive equilibrium is described by a set of labor allocations, $l_{i}$ and $l_{m 1}$, a loan size, $k$, and a value, $v$, for each firm, a set of active firms, $\mathcal{A}(w)$, and a wage rate, $w$, such that:

1. The loan, $k$, offered by the intermediary maximizes the value of a firm, $v$, in line with $\mathrm{P}(2)$, given the prices $\tilde{r}$ and $w$. The intermediary hires labor for monitoring in the amount $l_{m 1}$, as also specified by $\mathrm{P}(2)$.

2. A firm is offered a loan if and only if it lies in the active set, $\mathcal{A}(w)$, as defined by Eq. (4).

3. A firm hires labor, $l_{i}$, to maximize its profits in accordance with $\mathrm{P}(1)$, given wages, $w$, and the size of the loan, $k$, offered by the intermediary.

4. The wage rate, $w$, is determined so that the labor market clears, in accordance with (5).

\section{Discussion}

The analysis focuses on the role that intermediaries play in producing information. Before an investment opportunity is funded, intermediaries assess its risk and return. In the current setting, this amounts to knowing a project's type, $\tau$. This can be costlessly discovered in the model here. It would be easy to add a variable cost for a loan that is a function of $z$. $^{5}$ Doing so would have little benefit in the current context, however.

Intermediaries need to have systems in place to monitor cash flows or face the prospect of lower-than-promised returns. This is true regardless of whether investment funds are internally or externally generated. In times past, banks required borrowers to keep their funds in an account with them so that transactions could be monitored. Even a privately funded firm needs to be monitored, unless the scale is so small that the owner can operate it himself. Family-owned firms may mitigate the monitoring problem and are prevalent in poorer countries; see Caselli and Gennaioli (forthcoming) for a model of family-owned enterprises.

Managers and workers tend to siphon funds from the providers of capital, regardless of whether they are banks, bondholders, private owners, shareholders, or venture capitalists. At the micro level, this is what a shirking worker in a fast-food restaurant does. Computer surveillance software, called HyperActive Bob, designed to catch such a person is available from HyperActive Technologies for $\$ 200$ a month. ${ }^{6}$ In a dynamic contracting setting, with monitoring, it may appear at some points in time that the firm is relying heavily on internally generated funds to finance investments. This is especially true

\footnotetext{
${ }^{5}$ One could think about $\tau$ as representing the activity, industry, or sector within which a firm operates. For instance, Castro et al. (2009, Fig. 3) present data suggesting that the capital-goods sector is riskier than the consumption-goods one. As just discussed, it would be possible to have a screening stage where the intermediary verifies the initial type of a firm. It may not be possible to detect perfectly a firm's type. Even so, it may be feasible to design a contract that will reveal it. The ability to screen, albeit imperfectly, may play an important role in designing such a contract. See the classic paper by Boyd and Prescott (1986) for such an approach.

6 "Machines that can see." The Economist, March 5, 2009.
} 
for older firms. Yet starting the firm may have required funding from outside investors. Without the ability to monitor cash flows, investors may find that projects that require large upfront funds for payoffs that occur far in the future may deliver very disappointing returns. In fact, starting such a venture may not be feasible if investors cannot monitor the cash flows during the critical stages of the enterprise's development; see Cole et al. (2012) for an example. Measures of external financing also survey firms relatively late in their growth cycles. They do not capture the fact that start-ups use capital from private investors, such as venture capitalists.

The efficiency of monitoring, $z$, is likely to depend on the state of technology in the financial sector, both in terms of human and physical capital. Better information technologies allow for larger quantities of financial information to be collected, exchanged, processed, and analyzed. Indeed, the most information technology intensive industry in the United States is Depository and Nondepository Financial Institutions. Computer equipment and software services accounted for 10 percent of value added over the period 1995 to 2000, as opposed to 5 percent in Industrial Machinery and Equipment, or 2.6 percent in Radio and Television Broadcasting. Berger (2003) discusses the importance of IT in accounting for productivity gains in the U.S. banking sector. This is reflected in the growth of automated teller machines, Internet banking, electronic payment technologies, and information exchanges that permit the use of economic models to undertake credit scoring for small businesses, develop investment strategies, create new exotic financial products, etc. Similarly, a more talented workforce allows for higher-quality information workers: accountants, financial analysts, and lawyers. Last, the efficiency of monitoring depends on the legal environment, which specifies what information can, must, or must not be produced. This factor is separate from regulating the terms of payments, especially in bankruptcy as analyzed in Castro et al. (2009). That is, in the current setting, a firm must pay the amount $r_{1} k$ in the low state, but one could imagine that limited investor protection might reduce this to some smaller amount.

Before proceeding to the quantitative analysis, some mechanics of the above framework are inspected in a heuristic manner; for a more formal analysis, see Greenwood et al. (2010). The presence of diminishing returns to information production leads to a financial theory of firm size, as will be discussed. In fact, the diminishing returns to information production can be thought of as providing a microfoundation for the Lucas (1978) span of control model. The framework also specifies a link between the state of financial development and the state of economic development. Some of the mechanics are detailed now.

1. A firm's production is governed by constant returns to scale. In the absence of financial market frictions, no rents would be earned on production. Additionally, in a frictionless world only firms offering the highest expected return would be funded. In this situation, $\max _{\tau \in \mathcal{T}}\left[\pi_{1} r_{1}(\tau)+\pi_{2} r_{2}(\tau)\right]=\tilde{r}-\mathrm{cf}$. (4). With financial market frictions, $\pi_{1} r_{1}(\tau)+\pi_{2} r_{2}(\tau)>$ $\tilde{r}$ for all funded projects $\tau \in \mathcal{A}(w)$, a fact easily gleaned from Eq. (3). Thus, deserving projects-those $\tau \in \mathcal{B}(w) \equiv$ $\left\{x: \max _{x \in \mathcal{T}}\left[\pi_{1} r_{1}(x)+\pi_{2} r_{2}(x)\right]\right\}$-will be underfunded, while undeserving projects-those funded $\tau \notin \mathcal{B}(w)-$ are simultaneously overfunded. Funded firms will earn rents, $v$, as given by $\mathrm{P}(2)$.

2. What determines the size of a firm's loan? By glancing at the left-hand side of Eq. (3), which details the intermediary's profits, it looks likely that the firm's loan will be increasing in the project's expected return, $\pi_{1} r_{1}(\tau)+\pi_{2} r_{2}(\tau)$, ceteris paribus. This is true: Recall that the odds of detecting fraud, $P_{21}\left(l_{m 1}, k, z\right)$, decrease in loan size, $k$. Therefore, more labor must be allocated to monitor the project in response to an increase in loan size. Similarly, a firm's loan will decrease in the project's risk, as measured by $r_{2}(\tau)-r_{1}(\tau)$; note that the variance in returns for a type- $\tau$ firm is given by $\pi_{1} \pi_{2}\left[r_{2}(\tau)-\right.$ $\left.r_{1}(\tau)\right]^{2}$. When the spread between the high and low states widens, the incentive is stronger for the firm to misreport its returns. Recall that the gain from lying is given by the objective function in $\mathrm{P}(2)$. To counter this the intermediary must devote more labor to monitoring. Diminishing returns to information production imply that loan size, $k$, is uniquely specified as a function of expected return, $\pi_{1} r_{1}(\tau)+\pi_{2} r_{2}(\tau)$, and risk, $r_{2}(\tau)-r_{1}(\tau)$.

3. Imagine that aggregate productivity, $x$, grows over time at the constant rate $g^{1 / \alpha}$ and let financial sector productivity, $z$, improve at the fixed rate $g$. Will there be balanced growth? Conjecture that along a balanced growth path the $k$ 's, $o$ 's, and $w$ will all grow at rate $g$. Also guess that $\mathcal{A}(w)$ and the $l_{i}$ 's, $l_{m 1}$ 's, and $r_{i}(\tau)$ 's will remain constant. This conjectured solution is verified in a heuristic manner. It is easy to see from the isoelastic forms of problem $\mathrm{P}(1)$ and Eq. (1) that the conjectured solution for balanced growth path will be satisfied for the $l_{i}$ 's and $r_{i}(\tau)$ 's. Since the $r_{i}(\tau)$ 's remain constant so does the active set, $\mathcal{A}(w)$, which is spelled out in (4). What about the $k$ 's and the $l_{m 1}$ 's? The solution guessed for $k$ and $l_{m} 1$ is consistent with $\mathrm{P}(2)$, if $P_{21}$ does not change along a balanced growth path. From Eq. (2) it is clear that the odds of getting caught cheating, $P_{21}$, will change over time, however, unless $z$ grows at precisely the rate $g$. This is assumed, though. Since the $l_{i}$ 's and $l_{m 1}$ 's remain fixed, if the labor-market-clearing condition (5) holds at one point along the balanced path it will hold at all others. Thus, the hypothesized solution for $w$ is consistent with labor-market clearing. Thus, the conjectured solution for balanced growth occurs.

4. Consider the case where $x$ grows at a different rate than $z$. Specifically, for illustrative purposes, take the extreme situation where $z$ rises while $x$ remains fixed. Thus, there is only financial innovation in the economy. According to (2) the odds of detecting fraud will rise, other things equal. The rents that firms accrue will drop, a fact that is evident from the objective function in $\mathrm{P}(2)$. This makes it feasible for financial intermediaries to offer firms larger loans, ceteris paribus, as can be gleaned from Eq. (3). The implied increase in the economy's aggregate capital stock will then drive up wages. Thus, inefficient firms will have their funding cut, as (4) makes clear. The active set of firms, $\mathcal{A}(w)$, thus shrinks. Therefore, financial innovation operates to cull unproductive firms. Average firm size in the economy is the total stock of labor (1) divided by the number of firms (or the measure of the active set). Therefore, average firm size increases. (The last two statements ignore the small amount of labor used in monitoring.) If $z$ increases without bound, then the economy will 
enter into a frictionless world where only firms offering the highest expected return, $\max _{\tau \in \mathcal{T}}\left[\pi_{1} r_{1}(\tau)+\pi_{2} r_{2}(\tau)\right]$, are funded. These firms will earn no rents; that is, $\max _{\tau \in \mathcal{T}}\left[\pi_{1} r_{1}(\tau)+\pi_{2} r_{2}(\tau)\right]=\tilde{r}$.

\section{The United States and Taiwan}

The quantitative analysis will now begin. To simulate the model, values must be assigned to its parameters. In a nutshell, these parameter values are based solely on information about the U.S. economy, with two exceptions. The U.S. information is from either the literature or stylized facts about the U.S. establishment-size distributions. The exceptions are the countryspecific levels of productivity in the production and financial sectors, or $x$ and $z$. These two variables are chosen so that the model matches a country's income and its spread between borrowing and lending rates. It is obvious that the level of TFP in a country, $x$, is tightly linked with its income. The spread between borrowing and lending rates reflects the costs of intermediation, at least in worlds where intermediation services are competitively provided. Thus, the interest-rate spread is connected to the level of efficiency in the financial sector, or $z$. So, the simulations will use a common set of parameter values for all countries, but for $x$ and $z$. The U.S., Taiwan, and later, 45 other countries each have their own levels of productivity for the production and financial sectors, or their own $x$ 's and $z$ 's.

\subsection{Fitting the model to the U.S. economy}

Some parameters are standard and thus can be chosen on the basis of a priori information. They are given conventional values. Capital's share of income, $\alpha$, is chosen to be 0.35 , a very standard number. ${ }^{7}$ Similarly, the depreciation rate, $\delta$, is set to 0.06 , another very common figure. ${ }^{8}$ The chosen value for the return on savings through an intermediary is $\tilde{r}=0.03$. $^{9}$

The rest of the parameters are chosen to minimize the distance between a set of stylized facts characterizing the U.S. establishment-size distributions for the years 1974 and 2004 and the model's predictions for these facts. This is done subject to a constraint that requires that the selected values for $x$ and $z$ must generate the observed level of incomes and the interest-rate spreads for these two years. As will be seen, the minimum distance estimation procedure amounts to selecting 11 parameters on the basis of 18 data targets. The literature provides no guidance on the appropriate choice of parameters governing the intermediary's monitoring technology $\psi$ and $\gamma$. Consequently, these parameters must be estimated. Similarly, little is known about the distribution of returns facing firms. Let $\mu_{\theta_{1}}$ be the mean across firms for the logarithm of the low shock, $\theta_{1}$; that is, $\mu_{\theta_{1}} \equiv \int \ln \left(\theta_{1}\right) d F\left(\theta_{1}, \theta_{2}\right)$. Analogously, $\mu_{\theta_{2}} \equiv \int \ln \left(\theta_{2}\right) d F\left(\theta_{1}, \theta_{2}\right)$. Likewise, $\sigma_{\theta_{i}}^{2}$ denotes the variance over firms for the shocks; that is, $\sigma_{\theta_{i}}^{2} \equiv \int\left[\ln \left(\theta_{i}\right)-\mu_{\theta_{i}}\right]^{2} d F\left(\theta_{1}, \theta_{2}\right)$, for $i=1,2$. In a similar vein, $\rho$ will represent the correlation between the low and high shocks, $\ln \left(\theta_{1}\right)$ and $\ln \left(\theta_{2}\right)$, in the type distribution for firms. Assume that these means and variances of firm-level $\ln$ (TFP) are distributed according to a bivariate truncated normal, $N\left(\mu_{\theta_{1}}, \mu_{\theta_{2}}, \sigma_{\theta_{1}}^{2}, \sigma_{\theta_{2}}^{2}, \rho\right)$. ${ }^{10}$ Normalize $\mu_{\theta_{1}}$ to be 1 . Of course, values for the parameters determining the productivities of the technologies used in the production and financial sectors, $x$ and $z$, are also needed.

Let TARGETS represent an $n$-vector of observations that the model should match. Similarly, M(PARAM) denotes the model's prediction for this vector, where PARAM $\equiv\left(x, z, \epsilon, \psi, \gamma, \mu_{\theta_{2}}, \sigma_{\theta_{1}}^{2}, \sigma_{\theta_{2}}^{2}, \rho\right)$. The calibration procedure minimizes the distance between the vectors TARGETS and M(PARAM). The key, then, is to choose targets that are tightly connected to the model's parameters. Two important targets in the analysis are the aggregate level of output, o, and the interest-rate spread, $\mathbf{s}$. For the model, define these quantities by ${ }^{11}$

$$
\mathbf{o} \equiv \int_{\mathcal{A}(w)}\left[\pi_{1} o_{1}\left(\theta_{1}, \theta_{2}\right)+\pi_{2} o_{2}\left(\theta_{1}, \theta_{2}\right)\right] d F\left(\theta_{1}, \theta_{2}\right),
$$

\footnotetext{
7 The value selected here lies in the middle of range used in the literature. Gomme and Rupert (2007) estimate a capital share toward the low end of the values used in literature for the United States, 0.283. In their analysis of the role of capital for economic development, King and Levine (1994) use an upper bound on the values found in the literature, 0.40 .

8 Examples are Cooley and Prescott (1995) and Li and Sarte (2004).

${ }_{9}^{9}$ For the period 1800 to 1990 , Siegel (1992) estimates the real return on bonds, with a maturity ranging from 2 to 20 years, to be between 3.36 percent (geometric mean) and 3.71 percent (arithmetic mean). He also estimates the real return on 90-day commercial paper to be between 2.95 percent (geometric mean) and 3.13 percent (arithmetic mean).

10 This is not true in a strict sense. First, the distribution is truncated. Specifically, draws for $\ln \left(\theta_{1}\right)$ and $\ln \left(\theta_{2}\right)$ are truncated to lie within two standard deviations from the mean. Second, the draw for $\ln \left(\theta_{2}\right)$ is further restricted to lie above the one for $\ln \left(\theta_{1}\right)$. Thus, the lower bound for $\ln \left(\theta_{2}\right)$ is set to $\max \left\{\mu_{\theta_{1}}+2 \sigma_{\theta_{1}}, \mu_{\theta_{2}}-2 \sigma_{\theta_{2}}\right\}$. These qualifications do not change the normal nature of the distribution by much.

11 Note that the value of the labor used in the financial sector has been left out of this measure of aggregate output; that is, output could have been measured as

$$
\mathbf{o} \equiv \int_{\mathcal{A}(w)}\left\{\pi_{1}\left[o_{1}\left(\theta_{1}, \theta_{2}\right)+w l_{m 1}\left(\theta_{1}, \theta_{2}\right)\right]+\pi_{2} o_{2}\left(\theta_{1}, \theta_{2}\right)\right\} d F\left(\theta_{1}, \theta_{2}\right) .
$$

This omission is of second-order importance. For the United States, the model predicts that financial sector output is about 6 percent of GDP. The maximum value obtained in the analysis is 7 percent for Turkey. The average value is 5.5 percent, with a standard deviation of 1.13 percentage points. So, this omission is small beer.
} 


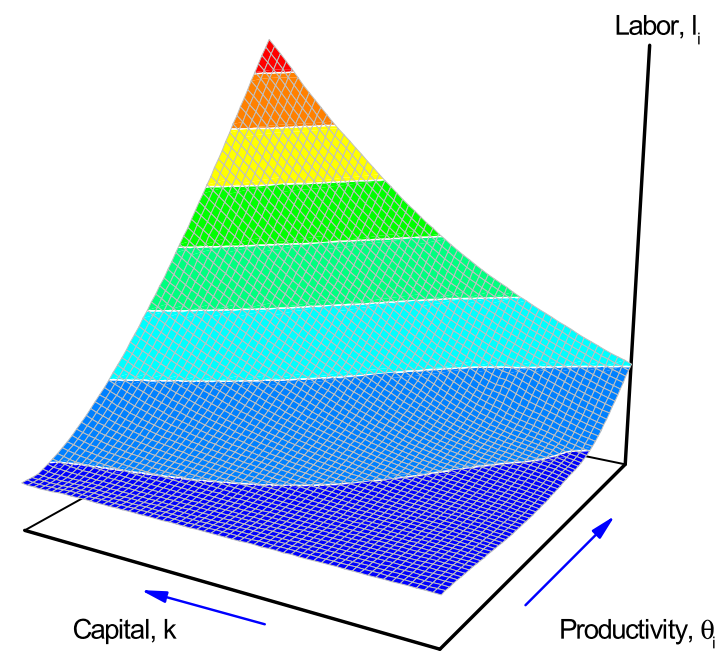

Fig. 4. Employment, $l_{i}$, as a function of capital, $k$, and the realized value of the technological shock, $\theta_{i}$-the model.

and

$$
\mathbf{s} \equiv \frac{w \int_{\mathcal{A}(w)} \pi_{1} l_{m 1}\left(\theta_{1}, \theta_{2}\right) d F\left(\theta_{1}, \theta_{2}\right)}{\int_{\mathcal{A}(w)} k\left(\theta_{1}, \theta_{2}\right) d F\left(\theta_{1}, \theta_{2}\right)} .
$$

The interest-rate spread, $\mathbf{s}$, represents the difference between what the intermediary earns on its loans and what it must pay its depositors. Because the intermediary earns zero profits this difference is solely accounted for by the cost of monitoring.

The technological parameters, $x$ and $z$, represent the efficiencies of the production and financial sectors. Think about the steady state for the model, which is defined formally in Definition 1, as providing a mapping between the aggregate level of output (per person), $\mathbf{o}$, and the interest-rate spread, $\mathbf{s}$, on the one hand, and the state of technology in its production and financial sectors, $x$ and $z$, on the other. Represent this mapping for the model's steady state by

$$
(\mathbf{o}, \mathbf{s})=O(x, z ; p),
$$

where $p \equiv\left(\epsilon, \psi, \gamma, \mu_{\theta_{2}}, \sigma_{\theta_{1}}^{2}, \sigma_{\theta_{2}}^{2}, \rho\right)$ represents the remaining seven parameters in PARAM (where $\mu_{\theta_{1}}$ is normalized to one and hence is omitted). While the states of the technologies in these sectors are unobservable directly, this steady-state mapping can be used to make an inference about $(x, z)$, given an observation on $(\mathbf{o}, \mathbf{s})$, by using the relationship

$$
(x, z)=O^{-1}(\mathbf{o}, \mathbf{s} ; p) .
$$

Given the importance of these two parameters, this condition is used as a constraint in the minimization of the distance between TARGETS and M(PARAM). Eq. (6) also plays an important role in the cross-country analysis.

The distribution of returns across firms is integrally related to the distribution of employment across them. Firms with high returns will have high employment, other things equal. Fig. 4 illustrates a firm's employment, $l_{i}$, as a function of its capital stock, $k$, and the realized value of the technological shock, $\theta_{i}$. A firm that receives a bigger loan, $k$, will hire more labor, $l_{i}$, other things equal. Recall that the size of the loan is determined before the technology shock is realized. Given the size of its loan, a firm will hire more labor the higher is the realized state of its technology shock. Given this relationship, the size distributions of firms for 1974 and 2004 are chosen as data targets to determine the remaining seven parameters.

Seven points on the distribution are picked for each year. As is well known, the size distribution of firms is highly skewed to the right; that is, there are many small firms, employing a relatively small amount of labor in total, and a few large ones, hiring many more workers. For instance, in 1974, the smallest 60 percent of establishments employed only 7.5 percent of the total number of workers, while the largest 5 percent of establishments hired about 60 percent of workers. Using only one target for the size distribution would be insufficient to capture this fact. It is important that the largest 12 percent of establishments employs 75 percent of the workers, but it is equally important that the truncated distribution inside the largest 12 percent of establishments is also very skewed-remember that the largest 5 percent of establishments employs about 60 percent of workers. Therefore, it is useful to consider the share of employment in the smallest 60, 75, 87, 95, 98, 99.3, and 99.7 percent of establishments. Thus, there are seven targets for each of the two years. Denote the $j$-th percentile target for the year $t$ by $e_{j, t}^{U S}$ and let $M_{j}\left(x_{t}^{U S}, z_{t}^{U S}, p\right)$ give the model's prediction for this statistic (all for $j=60,75,87,95,98,99.3,99.7$ and $t=1974,2004)$.

The mathematical transliteration of the above calibration procedure is

$$
\min _{p}\left\{\sum_{j=1}^{7} \frac{w_{j}}{2}\left[e_{j, 74}^{U S}-M_{j}\left(x_{74}^{U S}, z_{74}^{U S}, p\right)\right]^{2}+\sum_{j=1}^{7} \frac{w_{j}}{2}\left[e_{j, 04}^{U S}-M_{j}\left(x_{04}^{U S}, z_{04}^{U S}, p\right)\right]^{2}\right\},
$$



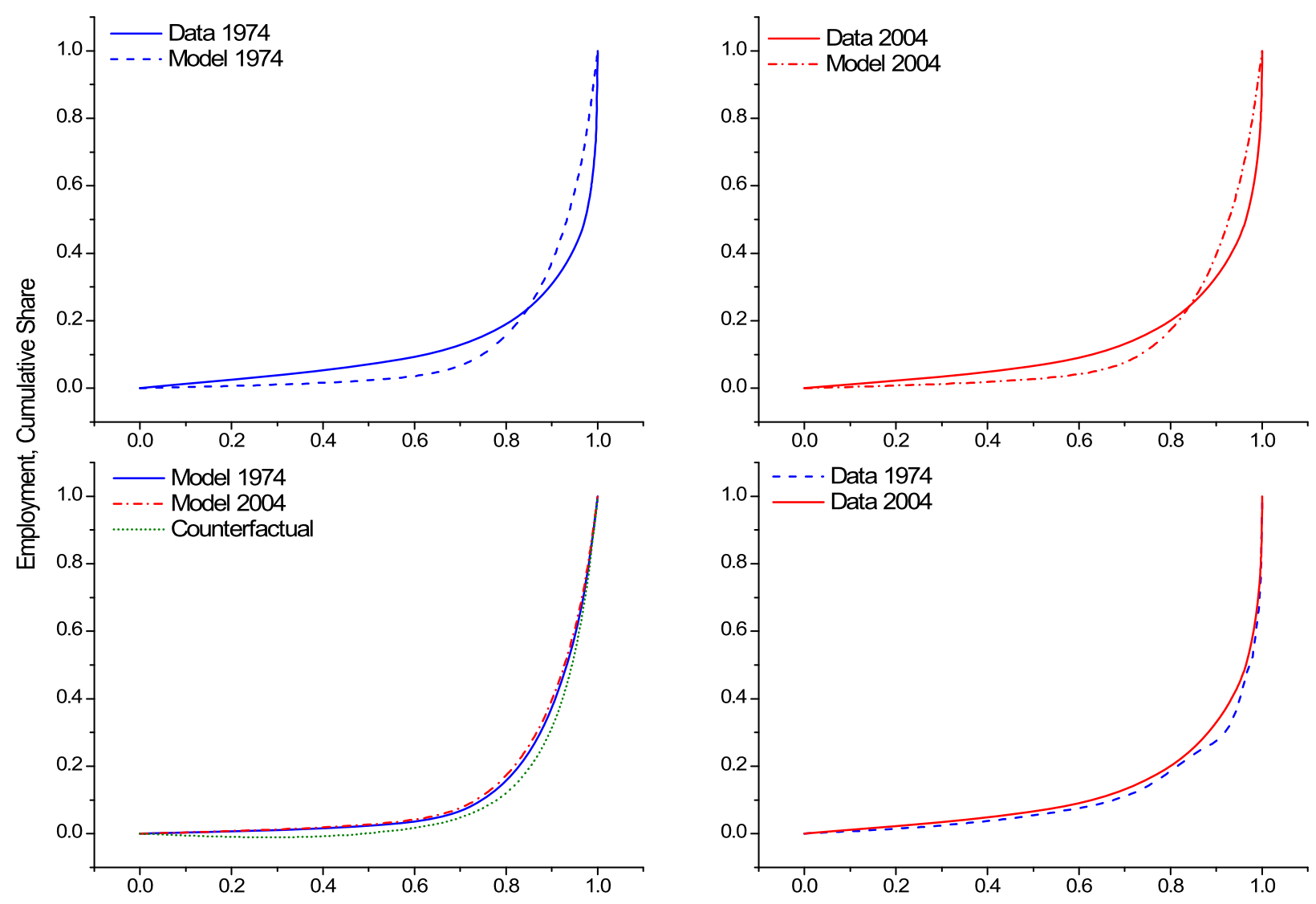

Establishments, Percentile

Fig. 5. Firm-size distributions, 1974 and 2004-U.S. data and model.

subject to

$$
\left(x_{74}^{U S}, z_{74}^{U S}\right)=0^{-1}\left(\mathbf{o}_{74}^{U S}, \mathbf{s}_{74}^{U S} ; p\right),
$$

and

$$
\left(x_{04}^{U S}, z_{04}^{U S}\right)=O^{-1}\left(\mathbf{o}_{04}^{U S}, \mathbf{s}_{04}^{U S} ; p\right) .
$$

Thus, following this strategy, 18 targets (including the $\mathbf{o}^{U S}$ 's and $\mathbf{s}^{U S}$ 's) are used to calibrate 11 parameters (including the $x^{U S}$ 's and $z^{U S}$ 's).

The upshot of the above fitting procedure is now discussed. First, there exists a set of technology parameters for the production and financial sectors, $\left(x_{74}^{U S}, z_{74}^{U S}, x_{04}^{U S}, z_{04}^{U S}\right)$, so that the model can match exactly the interest-rate spreads and percapita GDPs for the years 1974 and 2004. Second, the model matches very well the 1974 and 2004 firm-size distributions (see the upper two panels). Across time the size distribution shifts slightly to the left, as the lower-right panel of Fig. 5 shows. The largest firms account for slightly less of employment. Last, the parameters obtained from the fitting procedure are presented in Table 1.

\subsection{The United States, balanced growth}

It would be reasonable to argue, for the purposes of the current analysis, that the U.S. economy is characterized by a situation of balanced growth. First, there is only a small shift in the U.S. firm-size distribution between 1974 and 2004 (see the bottom-right panel in Fig. 5). Second, the economy's interest-rate spread shows only a modest decline (recall Fig. 1). Third, the capital-to-output ratio displays a small increase (again, Fig. 1).

Finance is important in the model. This can be gauged by asking the following counterfactual question: By how much would GDP have increased between 1974 and 2004 if there had been no technological progress in the financial sector? As the third panel of Table 2 shows output would have risen from $\$ 22,352$ to $\$ 34,530$ or by about 1.5 percent a year (when continuously compounded). This compares with the increase of 2.0 percent $(\$ 22,352$ to $\$ 41,208)$ that occurs when $z$ reaches its 2004 level. Thus, about 29 percent of growth is due to innovation in the financial sector. Likewise, the model predicts that 
Table 1

\begin{tabular}{lll} 
Parameter values. & & \\
\hline Parameter & Definition & Basis \\
\hline$\alpha=0.35$ & Capital's share of income & Standard \\
$\delta=0.06$ & Depreciation rate & Standard \\
$\tilde{r}=0.03$ & Return to savers & Siegel $(1992)$ \\
$\epsilon=32.57$ & Pr of detection, constant & Normalization \\
$\psi=0.96$ & Pr of detection, exp on capital & Calibrated to fit targets \\
$\gamma=0.57$ & Pr of detection, exp on labor & Calibrated to fit targets \\
$\mu_{\theta_{1}}=1.0$ & Mean of $\ln \left(\theta_{1}\right)$ & Normalization \\
$\mu_{\theta_{2}}=2.26$ & Mean of $\ln \left(\theta_{2}\right)$ & Calibrated to fit targets \\
$\sigma_{\theta_{1}}^{2}=0.70$ & Variance of $\ln \left(\theta_{1}\right)$ & Calibrated to fit targets \\
$\sigma_{\theta_{2}}^{2}=0.27$ & Variance of $\ln \left(\theta_{2}\right)$ & Calibrated to fit targets \\
$\rho=-0.80$ & Correlation $\ln \left(\theta_{1}\right)$ and $\ln \left(\theta_{2}\right)$ & Calibrated to fit targets \\
$x_{1974}=0.54, z_{1974}=10.76$ & TFP's, 1974 & Calibrated to fit targets \\
$x_{2004}=0.77, z_{2004}=26.44$ & TFP's, 2004 & Calibrated to fit targets
\end{tabular}

Table 2

The U.S. economy.

\begin{tabular}{lll}
\hline & Data & Model \\
\hline 1974 & & $3.07 \%$ \\
Spread, s & $3.07 \%$ & $\$ 22,352$ \\
GDP (per capita), o & $\$ 22,352$ & 1.00 \\
Capital-to-output ratio (indexed), k/o & 1.00 & 6.17 \\
TFP & & \\
2004 & & $2.62 \%$ \\
Spread, s & $2.62 \%$ & $\$ 41,208$ \\
GDP (per capita), o & $\$ 41,208$ & 1.09 \\
Capital-to-output ratio (indexed), k/o & 1.02 & 8.92 \\
TFP & & \\
2004 Counterfactual, $z_{2004}^{U S}=z_{1974}^{U S}$ & & 3.93 \\
Spread, s & 2.62 & $\$ 34,530$ \\
GDP (per capita), o & $\$ 41,208$ & 0.87 \\
Capital-to-output ratio (indexed), k/o & 1.02 & 8.59 \\
TFP & & \\
Yearly growth in financial productivity & & $2.58 \%$ \\
\hline
\end{tabular}

about 10 percent of TFP growth is due to improvement in financial intermediation. The financial system actually becomes a drag on development when $z$ is not allowed to increase. Wages rise as the rest of the economy develops. This makes monitoring more expensive; therefore, less monitoring will be done. As a consequence, interest rates rise and the economy's capital-to-output ratio drops. With no improvement in the financial system, the firm-size distribution actually moves over time in a direction (rightward) that is opposite to that shown in the data (leftward); this can be seen by comparing the lower two panels of Fig. 5. When there is no technological progress in the financial sector, there are more small inefficient firms. These small inefficient firms employ low amounts of capital and labor. The smallest firms in the economy (or the left tail) now account for a smaller fraction of the workforce (see the lower-left panel of Fig. 5).

Monitoring and the provision of financial services are abstract goods, so it is difficult to know what a reasonable change in $z$ should be. One could think about measuring productivity in the financial sector, as is often done, by $\mathbf{k} / \mathbf{l}_{m}$, where $\mathbf{k}$ is the aggregate amount of credit extended by the financial sector and $\mathbf{l}_{m}$ is the aggregate labor that it employs. By this traditional measure, productivity in the financial sector rose by 2.6 percent annually between 1974 and 2004. Berger (2003, Table 5) estimates that productivity in the commercial banking sector increased by 2.2 percent a year over this same period (which includes the troublesome productivity slowdown) and by 3.2 percent from 1982 to 2000.

\subsection{Taiwan, unbalanced growth}

Return now to the Taiwanese scenario shown in Fig. 1. Taiwan experienced a large drop in the interest-rate spread between 1974 and 2004 that was accompanied by a significant increase in the economy's capital-to-GDP ratio. This is clearly a situation of unbalanced growth. Recall that the steady state for the model provides a mapping between productivity in the production and financial sectors on the one hand, $x$ and $z$, and output and interest-rate spreads, $\mathbf{o}$ and $\mathbf{s}$, on the other. This mapping can be inverted to infer $x$ and $z$ using observations on $\mathbf{o}$ and $\mathbf{s}$ using Eq. (6), given a vector of parameter values, $p$. Take the parameter vector $p$ that was calibrated/estimated for the U.S. economy and use the Taiwanese data on per-capita GDPs and interest-rate spreads for the years 1974 and 2004, $\left(\mathbf{o}_{1974}^{T}, \mathbf{s}_{1974}^{T}, \mathbf{o}_{2004}^{T}, \mathbf{s}_{2004}^{T}\right)$, to obtain the imputed Taiwanese technology vector $\left(x_{1974}^{T}, z_{1974}^{T}, x_{2004}^{T}, z_{2004}^{T}\right)$. The results of the fitting exercise for Taiwan are shown in Table 3. 
Table 3

\begin{tabular}{lll} 
The Taiwan economy. & & \\
\hline & Data & Model \\
\hline 1974 & & $x_{1974}=0.14$ \\
Productivity, industrial & & $z_{1974}=0.40$ \\
Productivity, financial & $5.41 \%$ & $5.41 \%$ \\
Spread, s & $\$ 2211$ & $\$ 2211$ \\
GDP (per capita), o & 1.00 & 1.00 \\
Capital-to-output (indexed), k/o & & 1.55 \\
TFP & & \\
$\quad 2004$ & & $x_{2004}=0.35$ \\
Productivity, industrial & & $z_{2004}=15.64$ \\
Productivity, financial & $1.96 \%$ & $1.96 \%$ \\
Spread, s & $\$ 13,924$ & $\$ 13,924$ \\
GDP (per capita), o & 1.85 & 1.76 \\
Capital-to-output (indexed), k/o & & 4.20 \\
TFP & & \\
$\quad 2004$ Counterfactual, $z_{2004}^{T}=z_{1974}^{T}$ & & $10.43 \%$ \\
Spread, s & $1.96 \%$ & $\$ 6176$ \\
GDP (per capita), o & $\$ 13,924$ & 0.62 \\
Capital-to-output (indexed), k/o & 1.85 & 3.57 \\
TFP & & $9.90 \%$ \\
Yearly growth in financial productivity & & \\
\hline
\end{tabular}

How important was financial development for Taiwan's economic development? To answer this question, compute the model's solution for 2004 assuming there had been no financial development; that is, set $z_{2004}^{T}=z_{1974}^{T}$. Almost 45 percent of Taiwan's 6.3 percent annual rate of growth between 1974 and 2004 can be attributed to financial development; it also accounts for 16 percent of the growth in Taiwanese TFP. Taiwan had almost a 10 percent annual increase in the productivity of its financial sector, as conventionally measured.

\section{Cross-country analysis}

Move on now to the cross-country analysis. In particular, a sample of 45 countries, the intersection of all the nations in the Penn World Table and the Beck et al. $(2000,2001)$ dataset, will be studied. For each country $j$, a technology vector $\left(x^{j}, z^{j}\right)$ is backed out using data on per-capita GDP and interest-rate spreads $\left(\mathbf{o}^{j}, \mathbf{s}^{j}\right)$, given the procedure implied by Eq. (6) while setting $p$ to the estimated parameter vector for the U.S. economy. Erosa (2001) uses interest-rate spreads to quantify the effects of financial intermediation on occupational choice. It is not a forgone conclusion that this can always be done; that is, that a set of technology parameters can be found such that (6) always holds. ${ }^{12}$ (The cross-country results are reported in Table 9 in Appendix A.) By construction the model explains all the variation in output and interest-rate spreads across countries. ${ }^{13}$ Still, one could ask how well the measure for the state of technology in the financial sector that is backed out using the model correlates with independent measures of financial intermediation. Here, take the ratio of private credit by deposit banks and other financial institutions to GDP as a measure of financial intermediation as reported by Beck et al. $(2000,2001)$. (Other measures produce similar results but reduce the sample size too much.) Additionally, one could examine how well the model explains cross-country differences in capital-to-GDP ratios.

Table 4 reports the findings. The correlation between the imputed state of technology in the financial sector and the independent Beck et al. (2000, 2001) measure of financial intermediation is quite high (see Table 4). Thus, it appears reasonable to use the constructed values of $z$ to investigate the relationship between output and financial development. Now the backed-out measure for the efficiency of the financial sector correlates well with a country's adoption of information technologies (see the upper-left panel in Fig. 6). It also is strongly associated with a country's human capital (upper-right

\footnotetext{
12 Theoretically speaking, there is a maximum interest-rate spread that the model can match. When the financial sector becomes too inefficient, it no longer pays to monitor loans. When $z$ falls (relative to $x$ ) the aggregate volume of lending declines. The wage rate will decline along with the economy's capital stock. As this happens, the $r_{1}$ 's rise [see (1)]. Take the firms with the highest value of $r_{1}$ and denote this by $\bar{r}_{1}$. By definition, $\bar{r}_{1}=r_{1}(\bar{\tau})$, where $\bar{\tau}=\arg \max _{\tau \in \mathcal{T}}\left\{r_{1}(\tau)\right\}$. Eventually, $\bar{r}_{1}$ will hit $\tilde{r}$. At this point, a Williamson (1986)-style credit-rationing equilibrium emerges. In the credit-rationing equilibrium, $\bar{r}_{1}=\tilde{r}$. Here type- $\bar{\tau}$ firms will pay the fixed interest rate $\bar{r}_{1}$ and they will not be monitored. Because $r_{2}>\tilde{r}$ for these firms, they would demand as big a loan as possible. Thus, their credit must be rationed. The interest-rate spread on these loans will be zero. Note that $\bar{r}_{1}$ can never exceed $\tilde{r}$. because infinite profit opportunities would then emerge in the economy. Thus, the interest-rate spread is a $\cap$-shaped function of $z$. (The interest-rate spread also approaches zero as $z \rightarrow \infty$, or when the economy asymptotes to the frictionless competitive equilibrium. As $z \rightarrow 0$ the fraction of loans that are not monitored eventually approaches 1 , implying that the interest-rate spread will drop to zero.) The peak of the $\cap$ function is the maximum permissible interest-rate spread allowed by the model.

13 The model predicts a positive association between a country's rate of investment and its GDP; Castro et al. (2009, Fig. 1) show that this is true. As mentioned, it is stronger when investment spending is measured at international prices as opposed to domestic ones. This puzzle could be resolved here by adopting aspects of Castro et al.'s (2009) two-sector analysis.
} 
Table 4

Cross-country evidence.

\begin{tabular}{llll}
\hline & $\mathbf{k} / \mathbf{o}$ & $\begin{array}{l}z \text { with Beck et al. } \\
(2000,2001)\end{array}$ & $\begin{array}{l}\mathbf{k} / \mathbf{1}_{m} \text { with Beck et } \\
\text { al. }(2000,2001)\end{array}$ \\
\hline Corr(model, data) & 0.62 & 0.80 & 0.82 \\
\hline
\end{tabular}
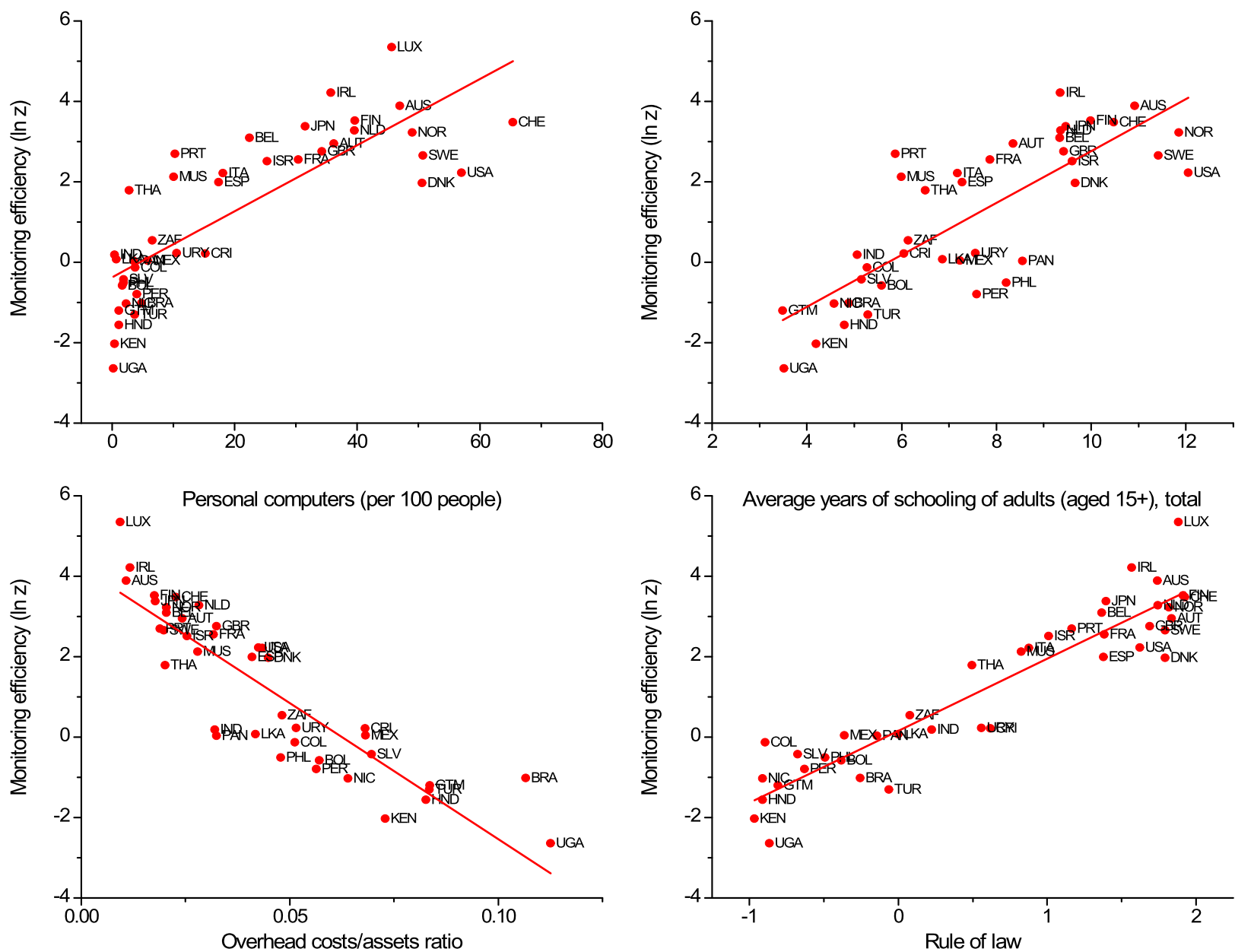

Fig. 6. The relationship between imputed $\ln (z)$ on the one hand, and measures of information technology, human capital, overhead costs to assets and the rule of law, on the other.

panel) and the maturity of its legal system (lower-right panel). These three factors should make intermediation more efficient for the reasons discussed in Section 3. Indeed, Fig. 6 (lower-left panel) also illustrates how the ratio of overhead cost to assets, a measure of efficiency, declines with the constructed $\ln (z)$. Another measure of financial efficiency for the model is $\mathbf{k} / \mathbf{l}_{m}$; this was discussed earlier. This too correlates well with the independent Beck et al. (2000, 2001) measure of financial intermediation.

As can be seen, the capital-to-output ratios predicted by the model are positively associated with those in the data. The correlation is reasonably large. That these two correlations are not perfect should be expected. Other factors, such as the big differences in public policies discussed in Parente and Prescott (2000), may explain a large part of the cross-country differences in capital-to-output ratios. Differences in monetary policies across nations may influence cross-country interestrate spreads. Additionally, there is noise in these numbers given the manner of their construction (see Appendix A).

Interestingly, Sri Lanka and the United States both have an interest-rate spread of about 4.2 percent. The model predicts the U.S. $z$ is about 215 percent higher (when ln differenced or continuously compounded) than Sri Lanka's-the former's $\ln (z)$ is 2.22 compared with 0.07 for the latter (see Table 9 in Appendix A). Recall that the units for $\ln (z)$ are meaningless since monitoring is abstract good. If one measures productivity in the financial sector by the amount of credit extended relative to the amount of labor employed in the financial sector, as discussed earlier, then the analysis suggests that intermediation in the United States is about 220 percent (continuously compounded) more efficient than in Sri Lanka. Why? The United States has a much higher level of income per worker and hence TFP than does Sri Lanka (\$33,524 versus \$3967). 

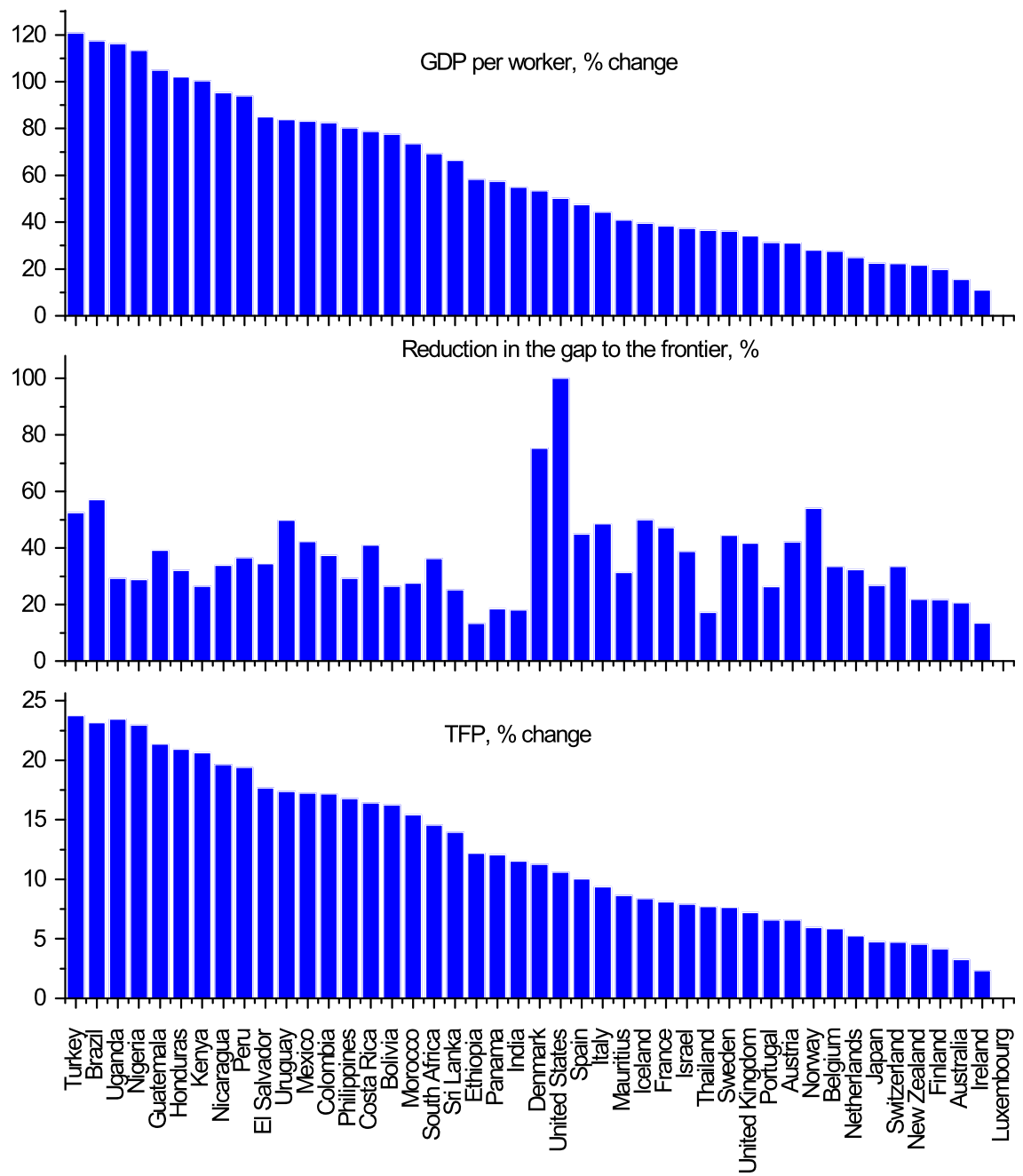

Fig. 7. Cross-country results showing the impact of a move to financial best practice on GDP per worker, the output gap, and TFP-the model.

Therefore, given the higher wages, monitoring will be more expensive in the United States. For both countries to have the same interest-rate spread, efficiency in the U.S. financial sector must be higher. Before proceeding on to a discussion of the importance of financial development for economic development, note that the findings do not change much if the model is matched up with capital-to-output ratios or overhead costs (see Fig. 6) instead of the Beck et al. (2000, 2001) interest-rate spreads. This is discussed in Section 6.

\subsection{The importance of financial development for economic development}

It is now possible to gauge how important efficiency in the financial sector is for economic development, at least in the model. To this end, let the best industrial and financial practices in the world be denoted by $\bar{x} \equiv \max \left\{x_{i}\right\}$ and $\bar{z} \equiv$ $\max \left\{z_{i}\right\}$, respectively. Represent country $i$ 's output, as a function of the efficiency in its industrial and financial sectors, by $\mathbf{o}_{i}=\mathbf{O}\left(x_{i}, z_{i}\right)$; this is really just the first component of the mapping $O(x, z, p)$. If country $i$ could somehow adopt the best financial practice in the world, it would produce $\mathbf{O}\left(x_{i}, \bar{z}\right)$. Similarly, if country $i$ used the best practices in both sectors, it would attain the output level $\mathbf{O}(\bar{x}, \bar{z})$. The shortfall in output from the inability to attain best practices is $\mathbf{O}(\bar{x}, \bar{z})-\mathbf{O}\left(x_{i}, z_{i}\right)$. The United States has the highest value for $x$ and Luxembourg for $z$.

The percentage gain in output for country $i$ by moving to the best financial practice is given by $100 \times\left[\ln \mathbf{O}\left(x_{i}, \bar{z}\right)-\right.$ $\ln \mathbf{0}\left(x_{i}, z_{i}\right)$ ]. The results for this experiment are plotted in Fig. 7. As can be seen, the gains are quite sizable. On average, a country could increase its GDP by 58 percent and TFP by 12 percent. The country with the worst financial system, Uganda, would experience a 116 percent rise in output and its TFP would increase by 23 percent. While sizable, these gains in GDP are small relative to the increase needed to move a country onto the frontier for income, $\mathbf{O}(\bar{x}, \bar{z})$. The percentage of the gap that is closed by a movement to best financial practice is measured by $100 \times\left[\mathbf{O}\left(x_{i}, \bar{z}\right)-\mathbf{O}\left(x_{i}, z_{i}\right)\right] /\left[\mathbf{O}(\bar{x}, \bar{z})-\mathbf{O}\left(x_{i}, z_{i}\right)\right]$. Fig. 7 plots the reduction in this gap for the countries in the sample. The average reduction in this gap is only 33 percent. 
Table 5

Worldwide move to best financial practice, $\bar{z}$.

$\begin{array}{lr}\text { Increase in world output (per worker), \% } & 53.3 \\ \text { Reduction in gap between actual and potential world output, \% } & 30.8 \\ \text { Increase in world TFP, \% } & 13.5 \\ \text { Fall in dispersion of ln(output) across countries, \% } & 22.8 \\ \text { Fall in (pop-wghtd) mean of (cap-wghtd) distortion, \% } & 14.7 \\ \text { Fall in (pop-wghtd) mean dispersion of (cap-wghtd) distortion, \% } & 9.5\end{array}$

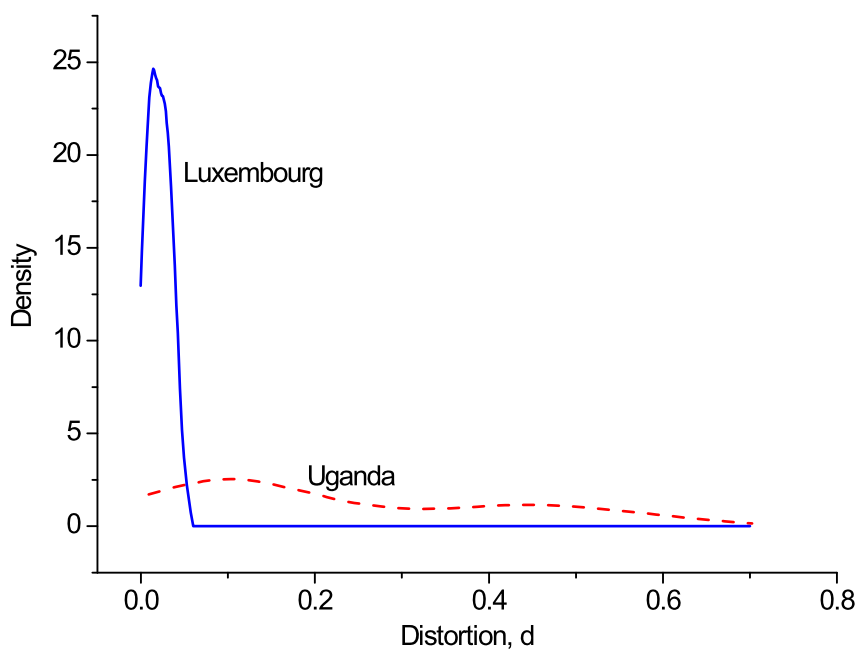

Fig. 8. The distribution of distortions, $d=\pi_{1} r_{1}+\pi_{2} r_{2}-\tilde{r}$, across establishments for Luxembourg and Uganda-the model.

For most countries the shortfall in output is accounted for by a low level of TFP in the nonfinancial sector. A more detailed breakdown of the cross-country results is presented in Table 9 in Appendix A.

Therefore, the importance of financial intermediation for economic development depends on one's outlook. World output would rise by 53 percent by moving all countries to the best financial practice (see Table 5). This is a sizable gain. Still, it would close only 31 percent of the gap between actual and potential world output. Dispersion in cross-country output would fall by about 15 percentage points from 77 percent to 62 percent. Financial development explains about 23 percent of cross-country dispersion in output by this metric.

Restuccia and Rogerson (2008) started a strand in the literature about the importance of idiosyncratic distortions that create heterogeneity in the prices faced by individual producers. Although they do not identify the sources of those distortions, they do show they can generate differences in TFP in the range of 30 to 50 percent. Guner et al. (2008) analyze the possible impact of size-dependent policies, such as the restrictions on retailing in Japan favoring small stores, on an economy. Here, the presence of informational frictions causes the expected marginal product of capital, $\pi_{1} r_{1}+\pi_{2} r_{2}$, to deviate from its user cost, $\tilde{r}$. The distortion is modeled endogenously. Define the induced distortion in investment by $d=$ $\pi_{1} r_{1}+\pi_{2} r_{2}-\tilde{r}$. For a country such as Uganda these deviations are fairly large. Fig. 8 plots the distribution of the distortion across plants for Luxembourg and Uganda. As can be seen, both the mean level of the distortion and its dispersion are much larger in Uganda than in Luxembourg. The (capital-weighted) mean level of this distortion is 21 percent (2 percent) for Uganda (Luxembourg). It varies greatly across plants, as indicated by a standard deviation of 18 percent (1.2 percent). If Uganda adopted Luxembourgian financial practice, the average size of this distortion would drop to 0.4 percent. Its standard deviation across plants collapses from 18 percent to just 0.3 percent. The elimination of this distortion results in capital deepening among the active plants. Average TFP would rise by 23 percent in the model as inefficient plants are culled. For the world at large, the average size of the distortion is 16.4 percent with an average coefficient of variation of 62 percent. The mean distortion drops to 1.7 percent with a worldwide movement to best financial practice. The average standard deviation across plants falls from 10.3 percent to a mere 0.8 percent.

Finally, the model predicts that larger firms should be found in countries with more developed financial systems. There does not appear to be a dataset that measures firm size in a consistent manner across countries. Beck et al. (2006) argue that the best available strategy is to use the size of the largest 100 companies in a country. They find a positive relationship exists between the development of a country's financial system and firm size, after controlling for the size of the economy, income per capita, and several firm and industry characteristics. As an example, their estimation implies that if Turkey had the same level of development in the financial sector as Korea (a country with a more developed financial system), the average size of the largest firms in Turkey would more than double. 
Table 6

Cross-country firm-size regressions.

\begin{tabular}{lcc}
\hline & Data & Model \\
\hline Interest-rate spread coefficient, $\eta$ & -22.4 & -16.6 \\
Standard error for $\eta$ & 2.35 & 6.55 \\
Number of country observations & 27 & 27 \\
$R^{2}$ & 0.80 & 0.53 \\
\hline
\end{tabular}

On this point, imagine running a regression of the following form for both the data and the model:

$$
\ln (\text { SIZE })=\text { CONSTANT }+\eta \times \text { SPREAD }+\iota \times \text { CONTROLS } .
$$

Firm size in the data is measured by average annual sales per firm (in U.S. dollars) for the top 100 firms, as taken from Beck et al. (2006). For the analogue in the model, simply use a country's GDP divided by the measure of active set $\mathcal{A}$ to obtain output per firm. [Once again the data for interest-rate spreads are obtained from Beck et al. $(2000,2001)$.] Controls are added for a country's GDP and population in the regression for the data, while for the model they are added just for GDP. ${ }^{14}$ The same list of countries is used for both the data and model.

The upshot of the analysis is shown in Table 6. A negative relationship is found in the cross-country data between the interest-rate spread and average firm size. The model also produces a negative relationship between these variables. The similarity between the size of the interest-rate spread coefficient, $\eta$, for the data and model is reassuring. Additionally, the data estimate of $\eta=-22$ implies that if a country with an interest-rate spread of 10 percentage points (which is among the worst 5 percent of nations in terms of financial development) could reduce its spread to just 3 percentage points (which would place it in the upper 5 percent of countries), then the average size of its top 100 firms would increase by 154 percent. This is roughly in accord with Beck et al.'s (2006) finding discussed above, given that Turkey had one of the worst financial systems while Korea had one of the best.

\section{Robustness analysis: Two alternative matching strategies}

Two alternative strategies for matching the model with international data will now be investigated. The story developed here has abstracted away from the importance of firm-level financing constraints studied by others. The importance of internal finance in the developed framework may not be as simple as it may first appear. While it may be tempting to draw on the familiar intuition developed elsewhere on the importance of internal finance-say in the debt default literature-it is questionable whether this carries over to the current setting. The central idea presented here is that unless the owners of a firm operate it themselves, they will always have to monitor cash flows. Otherwise, they run the risk that these flows will be expropriated by managers and workers. For example, imagine a publicly listed firm that raises all of the funds for its current investment from its cash flow. Does this mean that the firm's owners (the stockholders) do not need to monitor the company's cash flows-of course not. The point is that they own the sources of all revenue flows, including those used for internal finance, and need a mechanism to verify them. The assumption here is that the cost of monitoring capital raised from banks and other intermediaries (as measured by interest-rate spreads) is a good proxy for the cost of monitoring capital more generally, raised either externally or internally. Suppose, to the contrary, that internal funds do not need to be monitored. Then the importance of the mechanism outlined here would be exaggerated. Is there evidence of this in the analysis?

If internal funds do not require monitoring, then the model should overstate the impact of interest-rate spreads on capital-to-output ratios. If so, the model would then display a steeper relationship between capital-to-output ratios and interest-rate spreads than is observed in the data. There does not seem to be any evidence of this (see the right-panel of Fig. 9). Indeed, the model does quite well mimicking the relationship between capital-to-output ratios and interest-rate spreads. Suppose the model is matched up with the observed capital-to-output ratios, $\mathbf{k} / \mathbf{o}$, instead of the observed interestrate spreads, $\mathbf{s}$. If internal finance can be used to reduce the monitoring costs associated with external finance, then the backed-out values for the $z$ 's (the productivities of the monitoring technologies) should now be higher than under the baseline matching scheme for countries with high interest-rate spreads. In effect, the computed $z$ 's will reflect a mixture of low-cost internal finance and the high-cost external option. The estimated gains from moving to best financial practice should be much smaller. Table 7 reports the results. As can be seen, a worldwide move to best financial practice still leads to a sizable gain in world output and TFP and a large drop in the dispersion of output across countries. (A listing of the findings for each country is presented in Table 10 in Appendix A.)

Note that in a standard firm-dynamics model the steady-state capital-to-output ratio is barely affected by the presence of financing constraints. Productive firms can quickly accumulate their desired capital stocks in such a setting. Reversing this would require high death rates for firms or technology shocks that lack persistence. Indeed, a firm-dynamics model

\footnotetext{
14 The idea here is that larger countries, as measured by income or population, would tend to have larger firms. In a frictionless world firms could locate anywhere, so there would be no need for such a connection to hold. Nontraded goods, productivity differences across countries, restrictions on trade, transportation costs, and so on would all lead to a positive association between average firm size, on the one hand, and income or population, on the other.
} 

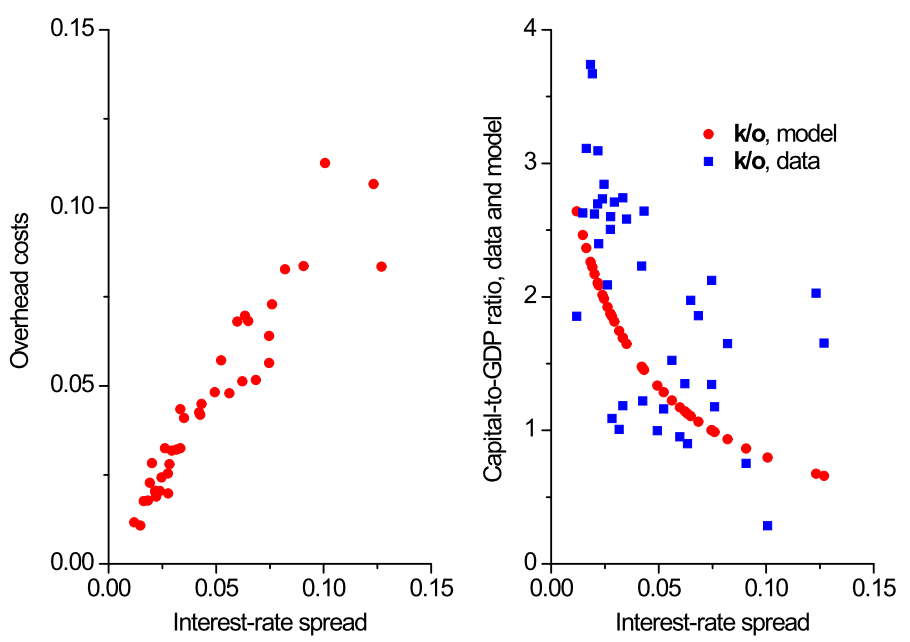

Fig. 9. The right panel shows the relationship between interest-rate spreads and capital-to-output ratios for the data and model. The left panel plots the relationship between interest-rate spreads and overhead costs for the data.

Table 7

Worldwide move to best financial practice, $\bar{z}$.

\begin{tabular}{llll}
\hline & \multicolumn{3}{l}{ Matching methodology } \\
\cline { 2 - 4 } \cline { 2 - 4 } & $\mathbf{s}$ & $\mathbf{k} / \mathbf{0}$ & $\phi$ \\
\hline Increase in world output (per worker), \% & 53.25 & 48.26 & 52.12 \\
Reduction in gap between actual and potential world output, \% & 30.80 & 25.60 & 37.01 \\
Increase in world TFP, \% & 13.47 & 14.28 & 13.10 \\
Fall in dispersion of ln(output) across countries, \% & 22.83 & 32.82 & 13.82 \\
\hline
\end{tabular}

with financial constraints may have difficulty accounting for the observed pattern of capital-output ratios and interest-rate spreads (Fig. 9). Such models often emphasize a different mechanism: the impact that financing constraints have on TFP, through the selection of entrepreneurs, as opposed to the impact on the aggregate capital-to-output ratio.

One could also argue that the financial sector is not competitive in less-developed countries and that this accounts for their high interest-rate spreads. Suppose that the financial sector is monopolized in some countries. Intuitively, one may expect that monopolies might charge borrowers higher interest rates on loans and offer depositors lower rates on their savings (relative to the situation of perfect competition). Therefore, such monopolistic practices would be reflected in interest-rate spreads. These monopolies should still try to minimize the costs of doing business. In other words, unless there are technological differences across countries, there should be no correlation between overhead costs and interest-rate spreads. Yet there is a strong one as Fig. 9 (left panel) displays. Furthermore, the findings are similar if these overhead costs, $\phi$, are used as a proxy for the efficiency of the financial sector instead of interest-rate spreads, $\mathbf{s}$ (shown in Table 7). (Table 11 in Appendix A gives the results for each country.) Thus, the model also works for a direct measure of financial efficiency. (Of course, one could make some type of $x$-efficiency argument, but developing this would require a quite different framework.) Overall the results appear to be remarkably robust to a variety of matching strategies.

\section{Conclusions}

Again, how important is financial development for economic development? To address this question, a costly state verification model is applied to both U.S. and cross-country data. The model has two unique features: First, financial intermediaries choose how much labor to devote to monitoring their loan activity. The odds of detecting malfeasance are a function of this choice. They also depend on the technology used in the financial sector. Second, each firm faces a distribution of returns. Furthermore, there is an economy-wide distribution across firms over these firm-specific distributions. These two features lead to a financial theory of firm size. This occurs because there are diminishing returns to scale in the monitoring activity. The framework is calibrated to fit the U.S. firm-size distributions for 1974 and 2004, as well as the observed intermediation spreads on loans.

The analysis suggests that financial intermediation is important for economic development. In particular, about 29 percent of U.S. growth can be attributed to technological improvement in financial intermediation. Since there was little change in the U.S. interest-rate spread, it appears that technological progress in the financial sector was in balance with technological advance in the rest of the economy. Roughly 45 percent of Taiwanese growth could be attributed to financial innovation. Given the dramatic decline in the Taiwanese interest-rate spread, technological progress in the financial sector may have outpaced that elsewhere. 
The model's predictions for the efficiency of financial intermediation in a cross-section of 45 countries match up well with independent measures. It performs reasonably well in mimicking cross-country capital-output ratios. The average measured distortion in the world between the expected marginal product of capital and its user cost is 14.7 percentage points. The average coefficient of variation in the distortion within a country is 62 percent. World output could increase by 53 percent if all countries adopted the best financial practice in the world. Adopting this leading-edge practice leads to funds being redirected away from inefficient firms toward more productive ones. This reallocation effect is reflected by a rise in world TFP by 13.5 percent. Still, this accounts only for 31 percent of the gap between actual and potential world output because the bulk of the differences in cross-country per-capita GDP are explained by the huge differences in the productivity of the nonfinancial sector. The results are robust to changes in the matching strategy for backing out the cross-country productivities in the financial and nonfinancial sectors.

\section{Acknowledgments}

Olga Itenberg, Diego Restuccia, Cezar Santos, and Stephen Williamson are thanked for helpful comments. The authors also thank Thorsten Beck for supplying the cross-country firm-size data used in Table 6. Feng Dong and Constanza Liborio provided exceptional research assistance and Judith Ahlers did an excellent job editing the manuscript. This research was supported by the NSF (award No. 0647766). The views expressed in this paper are those of the authors and do not necessarily reflect those of the Federal Reserve Bank of St. Louis or the Federal Reserve System.

\section{Appendix A. Data appendix}

- Fig. 1: For the United States the spread is computed along the lines of Mehra et al. (2009). Specifically, the spread is defined to be "Intermediation services associated with household borrowing and lending" divided by the "Total amount intermediated" (see definitions of these below). The "Intermediation services associated with household borrowing and lending" is computed as "Financial Monetary interest paid" minus "Financial Monetary interest received" minus "Financial services furnished without payment." These numbers are from the National Income and Product Accounts [NIPA, Tables 7.11 (lines 4 and 28) and 2.4.5 (line 88)]. The "Total amount intermediated" is from the U.S. Flow of Funds Accounts (2000, Table B.100.e). This number is Assets (line 1) minus Tangible Assets (line 2) minus equity of unincorporated business (line 29 in Table B.100). For Taiwan, the spread is imputed from Lu (2008, Fig. 2). The initial capital-to-GDP ratio in each country is normalized to 1 (to control for different definitions of the capital stock).

- Fig. 2, Fig. 3, and Section 5: The cross-country data for the interest-rate spreads are from the Financial Structure Dataset assembled by Beck et al. (2000, 2001) and revised in January 2009. It is defined as the accounting value of banks' net interest as a share of their interest-bearing (total earning) assets averaged over 1997 to 2003. The numbers for the financial development measure are from the same dataset. They represent demand, time, and saving deposits in deposit money banks as a share of GDP and are also averaged over 1997 to 2003. The other numbers derive from the Penn World Table (PWT), version 6.2 [see Heston et al. (2002)]. The aggregate capital stock for a country, k, is computed for the 1955-2003 sample period. The starting value is calculated using the formula $\mathbf{k}=\mathbf{i} /(g+\delta)$, where $\mathbf{i}$ is gross real investment in purchasing power parity terms (rgdpl*pop*ki in the PWT's notation or real income per capita $\times$ population $\times$ investment's share in total income), $g$ is the growth rate in investment, and $\delta$ is the rate of depreciation. The depreciation rate is taken to be 0.06 . For the starting value, $\mathbf{i}$ and $g$ are the average over the first five years available for each country (in general, 1950 to 1954). Thereafter, a time series is constructed for each country using the standard formula $\mathbf{k}^{\prime}=\mathbf{k}(1-\delta)+\mathbf{i}$. Again, the numbers used correspond to the average over 1997 to 2003 . A country's TFP is computed using TFP $=(\mathbf{o} / \mathbf{l}) /(\mathbf{k} / \mathbf{l})^{\alpha}$, where $\mathbf{o}$ is GDP, $\mathbf{l}$ is aggregate labor, and $\alpha$ is capital's share of income. A value of 0.35 is chosen for $\alpha$. All three letter country codes in the paper are taken from the International Organization for Standardization, to wit ISO 3166-1 alpha-3.

- Fig. 5 (firm size): The data are for establishments and are from County Business Patterns (CBP), which is released annually by the U.S. Census Bureau. Due to a significant shift in the methodology employed by the Census beginning in 1974, data are used only for 1974 and 2004. The horizontal axis orders establishments (from the smallest to highest) by the percentile in which they lie for employment. The vertical axis shows the cumulative contribution of this size of establishment to employment in the U.S. economy. Some data are shown in Table 8.

- Fig. 6 (relationship between $\ln z$ and some other variables): Data for the "rule of law" are from the World Bank's "Aggregate Governance Indicators, 1996-2008" [see Kaufmann et al. (2009)]. Data on personal computers are contained in the World Bank publication Information and Communications for Development 2009: Extending Reach and Increasing Impact. The numbers for the financial development measure and the ratio of overhead costs to assets are available in the revised version of the Beck et al. (2000) dataset mentioned above. In general, overhead costs are the indirect costs necessary to make a product or provide a service. Examples of such costs are depreciation, heat, light, indirect materials, indirect labor, insurance, and rent. Finally, average years of education is based on Barro and Lee (2001).

- Table 6: The cross-country data on the size of the largest 100 companies in a nation are derived from Beck et al. (2006); see that source for further details. The data were kindly supplied by Thorsten Beck. 
Table 8

U.S. establishment-size distribution data, 1974 and 2004.

\begin{tabular}{|c|c|c|c|c|c|c|c|c|c|}
\hline \multirow[b]{2}{*}{ Series } & \multicolumn{9}{|c|}{ Establishments with number of workers between: } \\
\hline & $1-4$ & $5-9$ & $10-19$ & $20-49$ & $50-99$ & $100-249$ & $250-499$ & $500-999$ & $1000+$ \\
\hline \multicolumn{10}{|l|}{ Year 1974} \\
\hline Establishments (in 1000s) & 2411 & 739 & 463 & 309 & 103 & 55.9 & 17.5 & 7.61 & 4.39 \\
\hline Employees (in 1000 s) & 4591 & 5222 & 6582 & 9714 & 7223 & 8615 & 6112 & 5286 & 10,153 \\
\hline Establishments & $59 \%$ & $18 \%$ & $11 \%$ & $7.5 \%$ & $2.5 \%$ & $1.4 \%$ & $0.5 \%$ & $0.2 \%$ & $0.1 \%$ \\
\hline Employees & $7.2 \%$ & $8.2 \%$ & $10 \%$ & $15 \%$ & $11 \%$ & $14 \%$ & $9.6 \%$ & $8.3 \%$ & $16 \%$ \\
\hline \multicolumn{10}{|l|}{ Year 2004} \\
\hline Establishments (in 1000s) & 4019 & 1406 & 933 & 637 & 218 & 122 & 31.3 & 11.5 & 6.83 \\
\hline Employees (in 1000s) & 6791 & 9311 & 12,598 & 19,251 & 15,037 & 18,314 & 10,662 & 7815 & 15,295 \\
\hline Establishments & $54 \%$ & $19 \%$ & $13 \%$ & $8.6 \%$ & $3.0 \%$ & $1.7 \%$ & $0.4 \%$ & $0.2 \%$ & $0.1 \%$ \\
\hline Employees & $5.9 \%$ & $8.1 \%$ & $11 \%$ & $17 \%$ & $13 \%$ & $16 \%$ & $9.3 \%$ & $6.8 \%$ & $13 \%$ \\
\hline
\end{tabular}

Source: U.S. Census Bureau County Business Patterns.

Table 9

Cross-country results, matching spreads-s.

\begin{tabular}{|c|c|c|c|c|c|c|c|c|c|c|c|c|c|}
\hline \multirow[t]{3}{*}{ Country } & \multicolumn{3}{|l|}{ Data } & \multicolumn{10}{|l|}{ Model } \\
\hline & \multirow[b]{2}{*}{$\mathbf{k} / \mathbf{o}$} & \multirow[b]{2}{*}{$\mathbf{s}$} & \multirow[b]{2}{*}{ GDPpc } & \multicolumn{4}{|c|}{ Benchmark } & \multicolumn{6}{|c|}{ Counterfactual } \\
\hline & & & & $x$ & $\ln (z)$ & $\mathbf{k} / \mathbf{o}$ & $\mathbf{s}$ & GDPpc & $\mathbf{s}$ & $\Delta \mathrm{GDP}$ & $\Delta$ Gap & $\Delta \mathrm{TFP}$ & $\Delta d$ \\
\hline UGA & 0.284 & 0.101 & 1.043 & 0.110 & -2.647 & 0.795 & 0.101 & 3.334 & 0.002 & 1.163 & 0.293 & 0.234 & 0.341 \\
\hline ETH & 0.372 & 0.031 & 0.705 & 0.058 & -1.117 & 1.753 & 0.031 & 1.263 & 0.001 & 0.583 & 0.134 & 0.122 & 0.104 \\
\hline NGA & 0.609 & 0.096 & 1.086 & 0.111 & -2.532 & 0.827 & 0.096 & 3.371 & 0.002 & 1.133 & 0.288 & 0.230 & 0.324 \\
\hline GTM & 0.751 & 0.091 & 3.786 & 0.245 & -1.202 & 0.863 & 0.091 & 10.814 & 0.004 & 1.050 & 0.391 & 0.213 & 0.299 \\
\hline SLV & 0.900 & 0.064 & 4.706 & 0.248 & -0.428 & 1.125 & 0.064 & 11.010 & 0.005 & 0.850 & 0.345 & 0.177 & 0.205 \\
\hline CRI & 0.951 & 0.060 & 8.093 & 0.346 & 0.210 & 1.172 & 0.060 & 17.777 & 0.006 & 0.787 & 0.409 & 0.164 & 0.188 \\
\hline ZAF & 0.997 & 0.049 & 8.207 & 0.327 & 0.543 & 1.334 & 0.049 & 16.400 & 0.006 & 0.692 & 0.363 & 0.145 & 0.153 \\
\hline IND & 1.006 & 0.032 & 2.630 & 0.136 & 0.185 & 1.745 & 0.032 & 4.551 & 0.003 & 0.548 & 0.180 & 0.115 & 0.100 \\
\hline MUS & 1.087 & 0.028 & 14.986 & 0.408 & 2.125 & 1.851 & 0.028 & 22.558 & 0.006 & 0.409 & 0.313 & 0.086 & 0.076 \\
\hline BOL & 1.160 & 0.052 & 2.929 & 0.171 & -0.584 & 1.284 & 0.052 & 6.363 & 0.003 & 0.776 & 0.264 & 0.163 & 0.170 \\
\hline KEN & 1.176 & 0.076 & 1.258 & 0.112 & -2.035 & 0.986 & 0.076 & 3.428 & 0.002 & 1.003 & 0.265 & 0.206 & 0.255 \\
\hline PAN & 1.184 & 0.033 & 2.479 & 0.133 & 0.029 & 1.693 & 0.033 & 4.399 & 0.003 & 0.574 & 0.185 & 0.121 & 0.106 \\
\hline LKA & 1.219 & 0.043 & 3.967 & 0.194 & 0.069 & 1.466 & 0.043 & 7.700 & 0.004 & 0.663 & 0.252 & 0.140 & 0.135 \\
\hline MAR & 1.276 & 0.049 & 3.835 & 0.199 & -0.214 & 1.336 & 0.049 & 7.991 & 0.004 & 0.734 & 0.275 & 0.154 & 0.158 \\
\hline NIC & 1.342 & 0.075 & 3.337 & 0.210 & -1.030 & 1.000 & 0.075 & 8.651 & 0.004 & 0.953 & 0.339 & 0.196 & 0.245 \\
\hline COL & 1.349 & 0.062 & 6.093 & 0.291 & -0.137 & 1.141 & 0.062 & 13.898 & 0.005 & 0.825 & 0.374 & 0.172 & 0.199 \\
\hline PHL & 1.524 & 0.056 & 3.565 & 0.198 & -0.506 & 1.224 & 0.056 & 7.954 & 0.004 & 0.802 & 0.293 & 0.168 & 0.182 \\
\hline HND & 1.649 & 0.082 & 2.273 & 0.170 & -1.560 & 0.932 & 0.082 & 6.309 & 0.003 & 1.021 & 0.320 & 0.209 & 0.273 \\
\hline TUR & 1.652 & 0.127 & 5.559 & 0.357 & -1.306 & 0.659 & 0.127 & 18.596 & 0.006 & 1.208 & 0.525 & 0.237 & 0.420 \\
\hline IRL & 1.854 & 0.012 & 24.344 & 0.465 & 4.212 & 2.640 & 0.012 & 27.173 & 0.007 & 0.110 & 0.134 & 0.023 & 0.017 \\
\hline URY & 1.858 & 0.069 & 10.269 & 0.423 & 0.229 & 1.065 & 0.069 & 23.742 & 0.007 & 0.838 & 0.497 & 0.174 & 0.215 \\
\hline MEX & 1.973 & 0.065 & 7.777 & 0.347 & 0.038 & 1.107 & 0.065 & 17.843 & 0.006 & 0.831 & 0.423 & 0.173 & 0.206 \\
\hline BRA & 2.027 & 0.123 & 7.067 & 0.412 & -1.024 & 0.675 & 0.123 & 22.873 & 0.007 & 1.175 & 0.571 & 0.232 & 0.405 \\
\hline GBR & 2.088 & 0.026 & 24.400 & 0.549 & 2.751 & 1.924 & 0.026 & 34.322 & 0.008 & 0.341 & 0.416 & 0.072 & 0.063 \\
\hline PER & 2.122 & 0.075 & 4.220 & 0.245 & -0.794 & 1.001 & 0.075 & 10.801 & 0.004 & 0.940 & 0.365 & 0.194 & 0.244 \\
\hline USA & 2.231 & 0.042 & 33.524 & 0.775 & 2.221 & 1.475 & 0.042 & 55.381 & 0.010 & 0.502 & 1.000 & 0.106 & 0.111 \\
\hline LUX & 2.362 & 0.009 & 45.830 & 0.676 & 5.344 & 2.844 & 0.009 & 45.830 & 0.009 & 0.000 & 0.000 & 0.000 & 0.000 \\
\hline PRT & 2.396 & 0.022 & 16.936 & 0.416 & 2.694 & 2.085 & 0.022 & 23.133 & 0.007 & 0.312 & 0.263 & 0.066 & 0.054 \\
\hline NZL & 2.487 & 0.017 & 20.605 & 0.446 & 3.366 & 2.325 & 0.017 & 25.584 & 0.007 & 0.216 & 0.219 & 0.046 & 0.036 \\
\hline ISR & 2.504 & 0.028 & 21.106 & 0.507 & 2.509 & 1.873 & 0.028 & 30.658 & 0.008 & 0.373 & 0.387 & 0.079 & 0.070 \\
\hline ILD & 2.567 & 0.031 & 25.071 & 0.582 & 2.504 & 1.779 & 0.031 & 37.243 & 0.008 & 0.396 & 0.499 & 0.084 & 0.077 \\
\hline ESP & 2.583 & 0.035 & 19.215 & 0.510 & 1.988 & 1.646 & 0.035 & 30.913 & 0.008 & 0.476 & 0.449 & 0.100 & 0.096 \\
\hline SWE & 2.599 & 0.028 & 24.582 & 0.560 & 2.657 & 1.871 & 0.028 & 35.275 & 0.008 & 0.361 & 0.445 & 0.076 & 0.068 \\
\hline NLD & 2.620 & 0.020 & 25.600 & 0.532 & 3.275 & 2.171 & 0.020 & 32.838 & 0.008 & 0.249 & 0.323 & 0.053 & 0.043 \\
\hline AUS & 2.628 & 0.015 & 25.993 & 0.503 & 3.887 & 2.463 & 0.015 & 30.361 & 0.008 & 0.155 & 0.205 & 0.033 & 0.025 \\
\hline DNK & 2.642 & 0.043 & 27.246 & 0.682 & 1.971 & 1.453 & 0.043 & 46.469 & 0.009 & 0.534 & 0.753 & 0.113 & 0.118 \\
\hline BEL & 2.695 & 0.022 & 24.228 & 0.522 & 3.091 & 2.105 & 0.022 & 31.933 & 0.008 & 0.276 & 0.334 & 0.058 & 0.049 \\
\hline FRA & 2.710 & 0.029 & 24.537 & 0.568 & 2.549 & 1.815 & 0.029 & 36.004 & 0.008 & 0.383 & 0.471 & 0.081 & 0.074 \\
\hline NOR & 2.734 & 0.024 & 32.896 & 0.651 & 3.220 & 2.014 & 0.024 & 43.567 & 0.009 & 0.281 & 0.539 & 0.059 & 0.052 \\
\hline ITA & 2.741 & 0.033 & 22.234 & 0.553 & 2.219 & 1.692 & 0.033 & 34.632 & 0.008 & 0.443 & 0.486 & 0.094 & 0.088 \\
\hline AUT & 2.842 & 0.025 & 26.433 & 0.569 & 2.947 & 1.985 & 0.025 & 36.093 & 0.008 & 0.312 & 0.421 & 0.066 & 0.057 \\
\hline THA & 3.093 & 0.022 & 6.659 & 0.226 & 1.789 & 2.100 & 0.022 & 9.597 & 0.004 & 0.366 & 0.173 & 0.077 & 0.061 \\
\hline FIN & 3.111 & 0.016 & 22.207 & 0.464 & 3.525 & 2.366 & 0.016 & 27.062 & 0.007 & 0.198 & 0.216 & 0.042 & 0.033 \\
\hline $\mathrm{CHE}$ & 3.670 & 0.019 & 28.363 & 0.562 & 3.476 & 2.221 & 0.019 & 35.463 & 0.008 & 0.223 & 0.334 & 0.047 & 0.039 \\
\hline JPN & 3.740 & 0.018 & 23.818 & 0.497 & 3.381 & 2.261 & 0.018 & 29.840 & 0.007 & 0.225 & 0.267 & 0.048 & 0.038 \\
\hline
\end{tabular}


Table 10

Cross-country results, matching capital/output ratios-k/o.

\begin{tabular}{|c|c|c|c|c|c|c|c|c|c|c|c|c|c|}
\hline \multirow[t]{3}{*}{ Country } & \multicolumn{3}{|l|}{ Data } & \multicolumn{10}{|c|}{ Model } \\
\hline & \multirow[b]{2}{*}{$\mathbf{k} / \mathbf{o}$} & \multirow[b]{2}{*}{$\mathbf{s}$} & \multirow[b]{2}{*}{ GDPpc } & \multicolumn{4}{|c|}{ Benchmark } & \multicolumn{6}{|c|}{ Counterfactual } \\
\hline & & & & $\bar{x}$ & $\ln (z)$ & $\mathbf{k} / \mathbf{o}$ & $\mathbf{s}$ & $\overline{\mathrm{GDPpc}}$ & $s$ & $\Delta \mathrm{GDP}$ & $\Delta$ Gap & $\Delta$ TFP & $\Delta d$ \\
\hline UGA & 0.284 & 0.101 & 1.043 & 0.171 & -4.182 & 0.288 & 0.325 & 6.938 & 0.000 & 1.895 & 0.459 & 0.329 & 1.125 \\
\hline ETH & 0.372 & 0.031 & 0.705 & 0.119 & -4.232 & 0.372 & 0.245 & 3.998 & 0.000 & 1.735 & 0.384 & 0.314 & 0.848 \\
\hline NGA & 0.609 & 0.096 & 1.086 & 0.128 & -3.070 & 0.609 & 0.140 & 4.438 & 0.000 & 1.408 & 0.344 & 0.273 & 0.483 \\
\hline GTM & 0.751 & 0.091 & 3.786 & 0.262 & -1.461 & 0.751 & 0.108 & 13.257 & 0.001 & 1.253 & 0.441 & 0.250 & 0.373 \\
\hline SLV & 0.900 & 0.064 & 4.706 & 0.277 & -0.903 & 0.900 & 0.086 & 14.440 & 0.001 & 1.121 & 0.428 & 0.228 & 0.296 \\
\hline CRI & 0.951 & 0.060 & 8.093 & 0.383 & -0.249 & 0.951 & 0.080 & 23.707 & 0.001 & 1.075 & 0.517 & 0.219 & 0.274 \\
\hline ZAF & 0.997 & 0.049 & 8.207 & 0.378 & -0.136 & 0.997 & 0.075 & 23.209 & 0.001 & 1.040 & 0.503 & 0.213 & 0.257 \\
\hline IND & 1.006 & 0.032 & 2.630 & 0.180 & -1.257 & 1.006 & 0.074 & 7.464 & 0.000 & 1.043 & 0.326 & 0.213 & 0.256 \\
\hline MUS & 1.087 & 0.028 & 14.986 & 0.535 & 0.654 & 1.087 & 0.067 & 39.400 & 0.001 & 0.967 & 0.661 & 0.200 & 0.227 \\
\hline $\mathrm{BOL}$ & 1.160 & 0.052 & 2.929 & 0.179 & -0.830 & 1.160 & 0.061 & 7.455 & 0.000 & 0.934 & 0.302 & 0.193 & 0.209 \\
\hline KEN & 1.176 & 0.076 & 1.258 & 0.103 & -1.644 & 1.176 & 0.060 & 3.180 & 0.000 & 0.928 & 0.235 & 0.191 & 0.206 \\
\hline PAN & 1.184 & 0.033 & 2.479 & 0.159 & -0.949 & 1.184 & 0.059 & 6.217 & 0.000 & 0.919 & 0.282 & 0.190 & 0.203 \\
\hline LKA & 1.219 & 0.043 & 3.967 & 0.213 & -0.409 & 1.219 & 0.057 & 9.700 & 0.000 & 0.894 & 0.320 & 0.185 & 0.195 \\
\hline MAR & 1.276 & 0.049 & 3.835 & 0.204 & -0.331 & 1.276 & 0.053 & 9.057 & 0.000 & 0.860 & 0.304 & 0.178 & 0.182 \\
\hline NIC & 1.342 & 0.075 & 3.337 & 0.182 & -0.341 & 1.342 & 0.049 & 7.586 & 0.000 & 0.821 & 0.277 & 0.170 & 0.169 \\
\hline $\mathrm{COL}$ & 1.349 & 0.062 & 6.093 & 0.268 & 0.274 & 1.349 & 0.049 & 13.737 & 0.001 & 0.813 & 0.344 & 0.169 & 0.167 \\
\hline PHL & 1.524 & 0.056 & 3.565 & 0.178 & 0.073 & 1.524 & 0.040 & 7.335 & 0.000 & 0.722 & 0.249 & 0.150 & 0.138 \\
\hline HND & 1.649 & 0.082 & 2.273 & 0.127 & -0.141 & 1.649 & 0.035 & 4.404 & 0.000 & 0.661 & 0.198 & 0.137 & 0.120 \\
\hline TUR & 1.652 & 0.127 & 5.559 & 0.227 & 0.759 & 1.652 & 0.035 & 10.700 & 0.001 & 0.655 & 0.267 & 0.136 & 0.119 \\
\hline IRL & 1.854 & 0.012 & 24.344 & 0.559 & 2.616 & 1.854 & 0.028 & 42.069 & 0.001 & 0.547 & 0.559 & 0.114 & 0.094 \\
\hline URY & 1.858 & 0.069 & 10.269 & 0.319 & 1.761 & 1.858 & 0.028 & 17.917 & 0.001 & 0.557 & 0.302 & 0.115 & 0.095 \\
\hline MEX & 1.973 & 0.065 & 7.777 & 0.258 & 1.700 & 1.973 & 0.025 & 12.973 & 0.001 & 0.512 & 0.242 & 0.106 & 0.085 \\
\hline BRA & 2.027 & 0.123 & 7.067 & 0.239 & 1.709 & 2.027 & 0.024 & 11.547 & 0.001 & 0.491 & 0.222 & 0.101 & 0.080 \\
\hline GBR & 2.088 & 0.026 & 24.400 & 0.526 & 3.065 & 2.088 & 0.022 & 38.399 & 0.001 & 0.453 & 0.465 & 0.094 & 0.073 \\
\hline PER & 2.122 & 0.075 & 4.220 & 0.167 & 1.376 & 2.122 & 0.021 & 6.672 & 0.000 & 0.458 & 0.168 & 0.094 & 0.073 \\
\hline USA & 2.231 & 0.042 & 33.524 & 0.625 & 3.663 & 2.231 & 0.019 & 49.824 & 0.001 & 0.396 & 0.602 & 0.082 & 0.062 \\
\hline LUX & 2.362 & 0.009 & 45.830 & 0.744 & 4.241 & 2.362 & 0.017 & 64.741 & 0.001 & 0.345 & 1.000 & 0.072 & 0.052 \\
\hline PRT & 2.396 & 0.022 & 16.936 & 0.387 & 3.317 & 2.396 & 0.016 & 24.038 & 0.001 & 0.350 & 0.261 & 0.072 & 0.053 \\
\hline NZL & 2.487 & 0.017 & 20.605 & 0.431 & 3.705 & 2.487 & 0.014 & 28.331 & 0.001 & 0.318 & 0.278 & 0.065 & 0.047 \\
\hline ISR & 2.504 & 0.028 & 21.106 & 0.436 & 3.765 & 2.504 & 0.014 & 28.857 & 0.001 & 0.313 & 0.279 & 0.064 & 0.046 \\
\hline ILD & 2.567 & 0.031 & 25.071 & 0.481 & 4.076 & 2.567 & 0.013 & 33.532 & 0.001 & 0.291 & 0.307 & 0.060 & 0.042 \\
\hline ESP & 2.583 & 0.035 & 19.215 & 0.404 & 3.846 & 2.583 & 0.013 & 25.668 & 0.001 & 0.290 & 0.238 & 0.059 & 0.042 \\
\hline SWE & 2.599 & 0.028 & 24.582 & 0.472 & 4.129 & 2.599 & 0.013 & 32.567 & 0.001 & 0.281 & 0.291 & 0.058 & 0.041 \\
\hline NLD & 2.620 & 0.020 & 25.600 & 0.483 & 4.218 & 2.620 & 0.012 & 33.680 & 0.001 & 0.274 & 0.296 & 0.056 & 0.039 \\
\hline AUS & 2.628 & 0.015 & 25.993 & 0.487 & 4.252 & 2.628 & 0.012 & 34.106 & 0.001 & 0.272 & 0.298 & 0.056 & 0.039 \\
\hline DNK & 2.642 & 0.043 & 27.246 & 0.501 & 4.330 & 2.642 & 0.012 & 35.579 & 0.001 & 0.267 & 0.308 & 0.055 & 0.038 \\
\hline BEL & 2.695 & 0.022 & 24.228 & 0.459 & 4.337 & 2.695 & 0.011 & 31.202 & 0.001 & 0.253 & 0.257 & 0.052 & 0.036 \\
\hline FRA & 2.710 & 0.029 & 24.537 & 0.462 & 4.385 & 2.710 & 0.011 & 31.459 & 0.001 & 0.249 & 0.256 & 0.051 & 0.035 \\
\hline NOR & 2.734 & 0.024 & 32.896 & 0.556 & 4.736 & 2.734 & 0.011 & 41.695 & 0.001 & 0.237 & 0.350 & 0.049 & 0.033 \\
\hline ITA & 2.741 & 0.033 & 22.234 & 0.430 & 4.362 & 2.741 & 0.011 & 28.289 & 0.001 & 0.241 & 0.225 & 0.049 & 0.034 \\
\hline AUT & 2.842 & 0.025 & 26.433 & 0.473 & 4.789 & 2.842 & 0.009 & 32.611 & 0.001 & 0.210 & 0.234 & 0.043 & 0.029 \\
\hline THA & 3.093 & 0.022 & 6.659 & 0.185 & 4.130 & 3.093 & 0.006 & 7.790 & 0.000 & 0.157 & 0.069 & 0.031 & 0.021 \\
\hline FIN & 3.111 & 0.016 & 22.207 & 0.403 & 5.394 & 3.111 & 0.006 & 25.582 & 0.001 & 0.142 & 0.132 & 0.028 & 0.019 \\
\hline CHE & 3.670 & 0.019 & 28.363 & 0.434 & 8.664 & 3.670 & 0.001 & 28.674 & 0.001 & 0.011 & 0.013 & 0.002 & 0.002 \\
\hline JPN & 3.740 & 0.018 & 23.818 & 0.384 & 9.339 & 3.740 & 0.001 & 23.818 & 0.001 & 0.000 & 0.000 & 0.000 & 0.000 \\
\hline
\end{tabular}

Table 11

Cross-country results, matching overhead costs $-\phi$.

\begin{tabular}{|c|c|c|c|c|c|c|c|c|c|c|c|c|c|}
\hline \multirow[t]{3}{*}{ Country } & \multicolumn{3}{|l|}{ Data } & \multicolumn{10}{|l|}{ Model } \\
\hline & \multirow[b]{2}{*}{$\mathbf{k} / \mathbf{o}$} & \multirow[b]{2}{*}{$\mathbf{s}$} & \multirow[b]{2}{*}{ GDPpc } & \multicolumn{4}{|c|}{ Benchmark } & \multicolumn{6}{|c|}{ Counterfactual } \\
\hline & & & & $x$ & $\ln (z)$ & $\mathbf{k} / \mathbf{o}$ & $\mathbf{s}$ & GDPpc & $\mathbf{s}$ & $\Delta \mathrm{GDP}$ & $\Delta$ Gap & $\Delta \mathrm{TFP}$ & $\Delta d$ \\
\hline UGA & 0.284 & 0.072 & 1.043 & 0.097 & -2.136 & 1.027 & 0.072 & 2.707 & 0.003 & 0.954 & 0.250 & 0.197 & 0.239 \\
\hline ETH & 0.372 & 0.024 & 0.705 & 0.053 & -0.591 & 2.030 & 0.024 & 1.107 & 0.002 & 0.451 & 0.107 & 0.095 & 0.075 \\
\hline NGA & 0.609 & 0.076 & 1.086 & 0.102 & -2.184 & 0.986 & 0.076 & 2.899 & 0.003 & 0.982 & 0.260 & 0.202 & 0.253 \\
\hline EGY & 0.638 & 0.018 & 4.481 & 0.167 & 1.751 & 2.281 & 0.018 & 5.966 & 0.005 & 0.286 & 0.121 & 0.060 & 0.046 \\
\hline GTM & 0.751 & 0.072 & 3.786 & 0.225 & -0.838 & 1.032 & 0.072 & 9.144 & 0.006 & 0.882 & 0.349 & 0.182 & 0.228 \\
\hline SLV & 0.900 & 0.040 & 4.706 & 0.212 & 0.374 & 1.536 & 0.040 & 8.397 & 0.006 & 0.579 & 0.251 & 0.122 & 0.118 \\
\hline CRI & 0.951 & 0.055 & 8.093 & 0.336 & 0.350 & 1.242 & 0.055 & 16.167 & 0.008 & 0.692 & 0.391 & 0.145 & 0.164 \\
\hline $\mathrm{ZAF}$ & 0.997 & 0.054 & 8.207 & 0.337 & 0.388 & 1.255 & 0.054 & 16.262 & 0.008 & 0.684 & 0.390 & 0.143 & 0.161 \\
\hline IND & 1.006 & 0.023 & 2.630 & 0.125 & 0.736 & 2.036 & 0.023 & 3.926 & 0.004 & 0.401 & 0.139 & 0.084 & 0.068 \\
\hline MUS & 1.087 & 0.027 & 14.986 & 0.403 & 2.207 & 1.895 & 0.027 & 20.913 & 0.009 & 0.333 & 0.289 & 0.071 & 0.063 \\
\hline $\mathrm{BOL}$ & 1.160 & 0.043 & 2.929 & 0.160 & -0.259 & 1.453 & 0.043 & 5.606 & 0.005 & 0.649 & 0.233 & 0.137 & 0.134 \\
\hline KEN & 1.176 & 0.054 & 1.258 & 0.099 & -1.479 & 1.259 & 0.054 & 2.790 & 0.003 & 0.797 & 0.220 & 0.167 & 0.176 \\
\hline
\end{tabular}


Table 11 (continued)

\begin{tabular}{|c|c|c|c|c|c|c|c|c|c|c|c|c|c|}
\hline \multirow[t]{3}{*}{ Country } & \multicolumn{3}{|l|}{ Data } & \multicolumn{10}{|l|}{ Model } \\
\hline & \multirow[b]{2}{*}{$\mathbf{k} / \mathbf{o}$} & \multirow[b]{2}{*}{$\mathbf{s}$} & \multirow[b]{2}{*}{ GDPpc } & \multicolumn{4}{|c|}{ Benchmark } & \multicolumn{6}{|c|}{ Counterfactual } \\
\hline & & & & $\bar{x}$ & $\ln (z)$ & $\mathbf{k} / \mathbf{o}$ & s & GDPpc & $\mathbf{S}$ & $\Delta \mathrm{GDP}$ & $\Delta$ Gap & $\Delta \mathrm{TFP}$ & $\Delta d$ \\
\hline PAK & 1.184 & 0.027 & 2.479 & 0.126 & 0.385 & 1.883 & 0.027 & 3.939 & 0.004 & 0.463 & 0.157 & 0.098 & 0.082 \\
\hline LKA & 1.219 & 0.040 & 3.967 & 0.191 & 0.165 & 1.516 & 0.040 & 7.226 & 0.005 & 0.600 & 0.242 & 0.126 & 0.122 \\
\hline MAR & 1.276 & 0.023 & 3.835 & 0.159 & 1.150 & 2.055 & 0.023 & 5.573 & 0.005 & 0.374 & 0.149 & 0.079 & 0.064 \\
\hline NIC & 1.342 & 0.076 & 3.337 & 0.212 & -1.057 & 0.987 & 0.076 & 8.383 & 0.006 & 0.921 & 0.347 & 0.190 & 0.244 \\
\hline $\mathrm{COL}$ & 1.349 & 0.085 & 6.093 & 0.326 & -0.631 & 0.906 & 0.085 & 15.522 & 0.008 & 0.935 & 0.456 & 0.191 & 0.269 \\
\hline PHL & 1.524 & 0.044 & 3.565 & 0.182 & -0.072 & 1.448 & 0.044 & 6.765 & 0.005 & 0.641 & 0.248 & 0.135 & 0.134 \\
\hline HND & 1.649 & 0.048 & 2.273 & 0.140 & -0.678 & 1.367 & 0.048 & 4.617 & 0.004 & 0.709 & 0.233 & 0.149 & 0.151 \\
\hline TUR & 1.652 & 0.065 & 5.559 & 0.278 & -0.291 & 1.110 & 0.065 & 12.398 & 0.007 & 0.802 & 0.374 & 0.167 & 0.201 \\
\hline PAN & 1.807 & 0.028 & 7.847 & 0.266 & 1.532 & 1.879 & 0.028 & 11.634 & 0.007 & 0.394 & 0.219 & 0.083 & 0.073 \\
\hline IRL & 1.854 & 0.011 & 24.344 & 0.457 & 4.440 & 2.736 & 0.011 & 24.865 & 0.010 & 0.021 & 0.032 & 0.005 & 0.003 \\
\hline URY & 1.858 & 0.087 & 10.269 & 0.461 & -0.142 & 0.891 & 0.087 & 25.210 & 0.010 & 0.898 & 0.587 & 0.183 & 0.268 \\
\hline ARG & 1.934 & 0.086 & 10.983 & 0.479 & -0.051 & 0.902 & 0.086 & 26.572 & 0.010 & 0.884 & 0.604 & 0.180 & 0.262 \\
\hline VEN & 1.946 & 0.082 & 7.216 & 0.359 & -0.402 & 0.934 & 0.082 & 17.756 & 0.008 & 0.900 & 0.478 & 0.184 & 0.256 \\
\hline MEX & 1.973 & 0.071 & 7.777 & 0.358 & -0.114 & 1.034 & 0.071 & 17.730 & 0.008 & 0.824 & 0.456 & 0.170 & 0.219 \\
\hline BRA & 2.027 & 0.077 & 7.067 & 0.346 & -0.329 & 0.977 & 0.077 & 16.893 & 0.008 & 0.871 & 0.458 & 0.179 & 0.240 \\
\hline GBR & 2.088 & 0.036 & 24.400 & 0.600 & 2.179 & 1.621 & 0.036 & 36.183 & 0.012 & 0.394 & 0.593 & 0.083 & 0.084 \\
\hline PER & 2.122 & 0.062 & 4.220 & 0.228 & -0.485 & 1.151 & 0.062 & 9.363 & 0.006 & 0.797 & 0.330 & 0.166 & 0.193 \\
\hline USA & 2.231 & 0.035 & 33.524 & 0.733 & 2.538 & 1.642 & 0.035 & 47.412 & 0.014 & 0.347 & 1.000 & 0.073 & 0.075 \\
\hline TTO & 2.283 & 0.036 & 13.600 & 0.410 & 1.597 & 1.622 & 0.036 & 21.425 & 0.009 & 0.455 & 0.364 & 0.096 & 0.094 \\
\hline LUX & 2.362 & 0.013 & 45.830 & 0.715 & 4.644 & 2.551 & 0.013 & 45.830 & 0.013 & 0.000 & 0.000 & 0.000 & 0.000 \\
\hline PRT & 2.396 & 0.021 & 16.936 & 0.410 & 2.793 & 2.136 & 0.021 & 21.419 & 0.009 & 0.235 & 0.228 & 0.050 & 0.042 \\
\hline NZL & 2.487 & 0.026 & 20.605 & 0.491 & 2.605 & 1.936 & 0.026 & 27.431 & 0.010 & 0.286 & 0.343 & 0.061 & 0.054 \\
\hline ISR & 2.504 & 0.025 & 21.106 & 0.494 & 2.687 & 1.967 & 0.025 & 27.716 & 0.010 & 0.273 & 0.337 & 0.058 & 0.052 \\
\hline ESP & 2.583 & 0.031 & 19.215 & 0.494 & 2.190 & 1.753 & 0.031 & 27.659 & 0.010 & 0.364 & 0.403 & 0.077 & 0.073 \\
\hline SWE & 2.599 & 0.032 & 24.582 & 0.583 & 2.394 & 1.731 & 0.032 & 34.770 & 0.012 & 0.347 & 0.528 & 0.073 & 0.071 \\
\hline CAN & 2.609 & 0.037 & 26.138 & 0.633 & 2.204 & 1.597 & 0.037 & 38.844 & 0.012 & 0.396 & 0.665 & 0.084 & 0.086 \\
\hline NLD & 2.620 & 0.025 & 25.600 & 0.562 & 2.855 & 1.954 & 0.025 & 33.080 & 0.011 & 0.256 & 0.416 & 0.054 & 0.049 \\
\hline AUS & 2.628 & 0.048 & 25.993 & 0.686 & 1.736 & 1.355 & 0.048 & 43.339 & 0.013 & 0.511 & 0.851 & 0.107 & 0.122 \\
\hline DNK & 2.642 & 0.040 & 27.246 & 0.668 & 2.090 & 1.515 & 0.040 & 41.804 & 0.013 & 0.428 & 0.773 & 0.090 & 0.096 \\
\hline BEL & 2.695 & 0.026 & 24.228 & 0.546 & 2.755 & 1.930 & 0.026 & 31.776 & 0.011 & 0.271 & 0.404 & 0.057 & 0.052 \\
\hline FRA & 2.710 & 0.034 & 24.537 & 0.594 & 2.272 & 1.667 & 0.034 & 35.645 & 0.012 & 0.373 & 0.567 & 0.079 & 0.078 \\
\hline NOR & 2.734 & 0.028 & 32.896 & 0.681 & 2.910 & 1.850 & 0.028 & 42.907 & 0.013 & 0.266 & 0.727 & 0.056 & 0.054 \\
\hline ITA & 2.741 & 0.045 & 22.234 & 0.606 & 1.700 & 1.417 & 0.045 & 36.602 & 0.012 & 0.499 & 0.658 & 0.105 & 0.115 \\
\hline AUT & 2.842 & 0.043 & 26.433 & 0.668 & 1.952 & 1.459 & 0.043 & 41.799 & 0.013 & 0.458 & 0.784 & 0.097 & 0.105 \\
\hline THA & 3.093 & 0.023 & 6.659 & 0.229 & 1.687 & 2.047 & 0.023 & 9.377 & 0.006 & 0.342 & 0.174 & 0.072 & 0.060 \\
\hline FIN & 3.111 & 0.016 & 22.207 & 0.462 & 3.576 & 2.391 & 0.016 & 25.219 & 0.010 & 0.127 & 0.168 & 0.027 & 0.022 \\
\hline $\mathrm{CHE}$ & 3.670 & 0.048 & 28.363 & 0.724 & 1.839 & 1.363 & 0.048 & 46.597 & 0.014 & 0.497 & 0.966 & 0.104 & 0.119 \\
\hline JPN & 3.740 & 0.017 & 23.818 & 0.489 & 3.527 & 2.333 & 0.017 & 27.333 & 0.010 & 0.138 & 0.200 & 0.029 & 0.024 \\
\hline
\end{tabular}

\section{References}

Barro, R.J., Lee, J.-W., 2001. International data on educational attainment: Updates and implications. Oxford Economic Papers 53, 541-563.

Beck, T., Demirgürç-Kunt, A., Levine, R., 2000. A new database on financial development and structure. World Bank Economic Review $14,597-605$.

Beck, T., Demirgürç-Kunt, A., Levine, R., 2001. The financial structure database. In: Demirgürç-Kunt, A., Levine, R. (Eds.), Financial Structure and Economic Growth: A Cross-Country Comparison of Banks, Markets, and Development. MIT Press, Cambridge, pp. 17-80.

Beck, T., Demirgürç-Kunt, A., Maksimovic, V., 2006. The influence of financial and legal institutions on firm size. Journal of Banking and Finance 30, 29953015.

Berger, A.N., 2003. The economic effects of technological progress: Evidence from the banking industry. Journal of Money, Credit, and Banking 35, 141-176. Boyd, J.H., Prescott, E.C., 1986. Financial intermediary-coalitions. Journal of Economic Theory 38, 211-232.

Buera, F.J., Kaboski, J.P., Shin, Y., 2011. Finance and development: A tale of two sectors. American Economic Review 101, 1964-2002.

Caselli, F., Gennaioli N., forthcoming. Dynastic management. Economic Inquiry. http://dx.doi.org/10.1111/j.1465-7295.2012.00467.x.

Castro, R., Clementi, G.L., MacDonald, G.M., 2009. Legal institutions, sectoral heterogeneity, and economic development. Review of Economics Studies 76, 529-561.

Cole, H.L., Greenwood, J., Sanchez, J.M., 2012. Why doesn't technology flow from rich to poor countries? Manuscript, Department of Economics, University of Pennsylvania.

Cooley, T.F., Prescott, E.C., 1995. Economic growth and business cycles. In: Cooley, T.F. (Ed.), Frontiers of Business Cycle Research. Princeton University Press, Princeton, pp. 1-38.

Erosa, A., 2001. Financial intermediation and occupational choice in development. Review of Economic Dynamics 4, 303-334.

Erosa, A., Hidalgo Cabrillana, A., 2008. On capital market imperfections as a source of low TFP and economic rents. International Economic Review 49, 437-473.

Goldsmith, R.W., 1969. Financial Structure and Development. Yale University Press, New Haven.

Gomme, P., Rupert, R., 2007. Theory, measurement and calibration of macroeconomic models. Journal of Monetary Economics 54, $460-497$.

Greenwood, J., Jovanovic, B., 1990. Financial development, growth, and the distribution of income. Journal of Political Economy 98, $1076-1107$.

Greenwood, J., Wang, C., Sanchez, J.M., 2010. Financing development: The role of information costs. American Economic Review 100, 1875-1891.

Guner, N., Ventura, G., Xu, D., 2008. Macroeconomic implications of size-dependent policies. Review of Economic Dynamics 11, 721-744.

Heston, A., Summers, R., Aten, A., 2002. Penn World Table, Version 6.1. Center for International Comparisons at the University of Pennsylvania (CICUP).

Kaufmann, D., Kraay, A., Mastruzzi, M., 2009. Governance matters VIII: Aggregate and individual governance indicators, 1996-2008. Policy Research Working Paper No. 4978, The World Bank. 
King, R.G., Levine, R., 1993. Finance and growth: Schumpeter might be right. Quarterly Journal of Economics 108, 717-736.

King, R.G., Levine, R., 1994. Capital fundamentalism, economic development, and economic growth. Carnegie-Rochester Conference Series on Public Policy 40, 259-292.

Levine, R., 2005. Finance and growth: Theory and evidence. In: Aghion, P., Durlauf, S.N. (Eds.), Handbook of Economic Growth, vol. 1A. Elsevier B.V., Amsterdam, pp. 865-934.

Li, W., Sarte, P.-D., 2004. Progressive taxation and long-run growth. American Economic Review 94, 1705-1716.

Lu, S., 2008. The role of capital market efficiency in long-term growth: A quantitative exploration. Working Paper, Department of Economics, National Tsing Hua University.

Lucas Jr., R.J., 1978. On the size distribution of business firms. Bell Journal of Economics 9, 508-523.

Mehra, R., Piguillem, F., Prescott, E.C., 2009. Intermediated quantities and returns. Working Paper No. 14351, National Bureau of Economic Research.

Midrigan, V., Xu, D., 2010. Finance and misallocation: Evidence from plant-level data. Manuscript, Department of Economics, New York University.

Parente, S.L., Prescott, E.C., 2000. Barriers to Riches. The MIT Press, Cambridge, MA.

Restuccia, D., Rogerson, R., 2008. Policy distortions and aggregate productivity with heterogeneous plants. Review of Economic Dynamics 11, 707-720.

Siegel, J.J., 1992. The real rate of interest from 1800-1990: A study of the U.S. and the U.K. Journal of Monetary Economics $29,227-252$.

Townsend, R.M., 1979. Optimal contracts and competitive markets with costly state verification. Journal of Economic Theory 21, 256-293.

Townsend, R.M., Ueda, K., 2010. Welfare gains from financial liberalization. International Economic Review 51, 553-597.

Williamson, S.D., 1986. Costly monitoring, financial intermediation, and equilibrium credit rationing. Journal of Monetary Economics 18, 159-179. 